\title{
SOBRE EL MODELO DE CONTRATACIÓN DE SERVICIOS REMUNERADOS EN EL DERECHO ROMANO. ALGUNOS ASPECTOS RELEVANTES DE LA LOCATIO CONDUCTIO*
}

\section{GONZALO SEVERIN FUSTER**}

RESUMEN: Este trabajo pretende dar cuenta de los principales aspectos que caracterizan el modelo de contratación remunerada de servicios en el Derecho romano. En la concepción romana, los servicios remunerados son una forma de arrendamiento (locatio conductio). Esa aproximación explica por qué la gran mayoría de los códigos decimonónicos consideraron los servicios como una forma de arrendamiento. Este trabajo, sin embargo, no pretende dar cuenta de la forma en que se produjo la recepción de la concepción unitaria romana del arrendamiento en las codificaciones civiles. La finalidad de este trabajo es, exclusivamente, sentar algunas bases que permitan, con posterioridad, abordar dicho estudio. En pos de esa finalidad, en este trabajo se abordan los siguientes aspectos de la locatio conductio: la delimitación externa del contrato; la división interna del contrato (el problema de la unidad o tripartición); y los principales aspectos sustantivos de la regulación romana sobre contratos de servicio.

PALABRAS CLAVE: Locatio conductio - arrendamiento - contratos de servicio - Derecho romano.

\section{SOME RELEVANT ASPECTS OF LOCATIO CONDUCTIO REgARDING THE MODEL OF REMUNERATED SERVICE CONTRACTS IN ROMAN LAW}

ABSTRACT: This paper aims to explain the main aspects that characterize service contracts in Roman Law. It is well known that paid services

\footnotetext{
* Este trabajo corresponde a una adaptación del primer capítulo de la tesis doctoral inédita titulada: Los contratos de servicio: la construcción histórica de la categoría y el derecho del cliente al cumplimiento especifico; que fue defendida en junio de 2014 en la Universidad Autónoma de Madrid, y realizada bajo la dirección de la profesora Nieves Fenoy Picón, a quien aprovecho de agradecer, por los comentarios y sugerencias realizados en su oportunidad. Los errores son, desde luego, de mi exclusiva responsabilidad.

Fecha de recepción: 5 de marzo de 2015.

Fecha de aceptación: 17 de abril de 2015.

** Profesor de Derecho civil, Pontificia Universidad Católica de Valparaíso (ChIle). Correo electrónico: gonzalo.severin@ucv.cl.
} 
were considered a form of lease (locatioconductio). This approach can explain why most part of the nineteenth century civil codes considered service contracts as a kind of "lease". However, this paper does not attempt to explain the reception of roman model in those civil codes, but to establish some basis upon which that study can be conducted instead. Towards this aim, the following issues of locatioconductio are addressed: its external delimitation; its internal division (the "unity or trichotomy" debate); and some key substantive aspects of the roman regulation of service contracts.

KEY WORDS: Locatio conductio - lease - service contracts - Roman law.

Sumario: Introducción. 1) La delimitación externa del tipo locatio conductio frente a otros contratos (depósito, mandato y compraventa). (1.1.) El carácter esencialmente oneroso de la locatio conductio. (1.1.1.) La locatio conductio y el contrato de depositum (depósito). (1.2.) La necesidad en la locatio conductio de que se entregue una cosa: distinción respecto de la compraventa. 2) La división interna del tipo locatio conductio (el problema de la unidad o tripartición). (2.1.) El problema de la unidad o tripartición de la locatio conductio: las distintas tesis de los autores. (2.1.1.) La tesis unitaria de la locatio conductio. (2.1.2) La tesis tripartita de la locatio conductio. (2.1.3.) La situación actual sobre el problema de la unidad o la tripartición de la locatio conductio. (2.2.) La diferencia entre la locatio conductio operarum y la locatio conductio operis. 3) Algunos aspectos sustantivos del modelo romano de la contratación de servicios. (3.1.) Dos advertencias previas. (3.2.) La descripción de los principales aspectos sustantivos del modelo romano de contratación de servicios. (3.2.1.) Las obligaciones del prestador del servicio. (3.2.2.) Las obligaciones de cliente. Conclusiones.

\section{INTRODUCCIÓN}

En el Derecho romano, el contrato consensual locatio conductio ${ }^{1}$ abarcaba una pluralidad de posibles objetos que, al menos visto ello des-

\footnotetext{
1 La locatio conductio es uno de los cuatro contratos consensuales, junto con la compraventa, el mandato y la sociedad [por todos, Schulz, F. (1969) Derecho romano clásico, Barcelona: Bosch., pp. 501-503]; y por lo demás, se dice así expresamente en GaYo 3.135: "Las obligaciones se contraen mediante acuerdo en las compraventas, arrendamientos o locaciones, sociedades y mandatos" [el texto para esta y todas las citas a las Instituciones de Gayo, están tomados de SAmper Polo, F. (2009) Instituciones jurídicas de Gayo, texto y traducción, México D. F: Editorial Jurídica de las Américas.].
} 
de una perspectiva moderna, responden a finalidades económicas muy distintas. En la locatio conductio se enmarcan tanto la cesión temporal del uso de alguna cosa, como la realización de diversas clases de actividades.

En las fuentes se califica como locatio conductio la entrega de una cosa con cargo a restituirla, finalizado su uso, sea que deba devolverse la misma cosa o solo el mismo género (D. 19.2.31). Así, por ejemplo, la entrega de un fundo (D. 19.2.3), de una vivienda (D. 19.2.5), de una habitación (D. 19.2.25) o de un esclavo (D. 19.2.43).

Pero también se califican como locatio conductio ciertas tareas o actividades, por ejemplo, confeccionar vasos de plata o anillos de oro (D. 19.2.31), lavar vestidos (D. 19.2.31), apacentar terneros (D. 19.2.9), remendar o limpiar alguna cosa (D. 19.2.9), transportar alguna cosa (D. 19.2.10), enseñar a un esclavo o a un aprendiz (D. 19.2.13), engastar o esculpir una piedra preciosa (D. 19.2.13), dar alojamiento (D. 19.2.13), custodiar alguna cosa (D. 19.2.40), o construir alguna cosa, como una casa (D. 19.2.30; D. 19.2.59) o un canal (D. 19.2.62).

Las razones que llevaron a los romanos a reunir esas distintas finalidades económicas, bajo el mismo y único tipo contractual, no es un punto claro $^{2}$. De hecho, ni siquiera está claro el origen de la locatio conductio $^{3}$. Ahora bien, lo que no se discute es la unidad "externa" del tipo

El carácter consensual del contrato locatio conductio le asemeja a la compraventa ["la locación y conducción, como es natural y de todas las gentes, no se celebra por palabras, sino por el consentimiento, como la compraventa" (D. 19.2.1)]. Esta asimilación a la compraventa no solo se basa en el carácter consensual, sino que también hay similitud en el contenido [ $L a$ locación y conducción es similar a la compraventa y se rige por las mismas reglas jurídicas" (D. 19.2.2)]. Los textos en espańol de estas y de todas las demás citas al Digesto (D.), así como al Código (Cód.) y a las Instituciones (Inst.) de Justiniano, están tomados de García DeL Corral, I. (1889) Cuerpo de Derecho Civil Romano, Barcelona: Jaime Molinas, editor.].

2 No obstante, el estudio de la cuestión de la unidad o tripartición de la locatio conductio ofrece algunas pistas sobre el origen de esta concepción unitaria romana (véase infra [11] y ss.) En todo caso, lo que sí parece claro es que la concepción unitaria del arrendamiento es de origen romano, puesto que no se encuentra en otros pueblos de la antigüedad. En el Derecho ateniense, por ejemplo, el arrendamiento de cosas, la confección de obras y la prestación de servicios, a diferencia de lo que ocurre en el Derecho romano, no se encajaban dentro de un único tipo contractual [para una aproximación a las diversas "formas" de arrendamiento en la antigua Atenas, véase Caillemer, E. (1869) Études sur les antiquités juridiques d'Athènes. Huitième étude: Le contrat de louage a Athènes, Paris: Durand-Thorin].

3 Desde luego, no es este el lugar para entrar en la cuestión del origen de la locatio conductio. Sobre el punto, Girard, por ejemplo, estima que, aunque es posible sostener que, al menos en lo que respecta a uno de sus "tipos" -la locatio conductio rei o "arrendamiento de cosas"el contrato consensual fue precedido de uno real (formado por la entrega de la cosa), el contrato posiblemente debió ser precedido de una doble estipulación, al igual que la venta [Girard, P. F. (1906) Manuel Élémentaire de Droit Romain, 4. a ed., Paris: Arthur Rousseau, éditeur, p. 566]. 
contractual. La propia terminología empleada en la denominación del contrato da cuenta de una cierta lógica tras esa unidad, pues, en la locatio conductio, una de las partes entrega o "coloca" ("locare"; y de ahí, la denominación de locator) una cosa en manos de la otra parte, quien la "lleva" ("conducere"; y de ahí que se le denomine conductor) a fin de hacer algo con ella (usarla, transformarla, transportarla, etc.) debiendo restituirla luego al locator 4 . Esta lógica (una parte "coloca" algo en manos de la otra) permite dar cabida a la prestación de actividades o servicios incluso cuando no hay propiamente "colocación" de un objeto material sobre el que deba trabajarse, en la medida que se considere que "lo que se coloca" es la propia persona, a disposición de las órdenes de otro ${ }^{5}$.

Desde luego, es en dicho modelo -el de la locatio conductio- en el que se halla la base de la aproximación legal que adoptaron la mayoría de los códigos civiles decimonónicos - tanto los europeos como los latinoamericanos- a la hora de regular los contratos de servicio (en un sentido amplio: "obras y servicios").

En el ámbito europeo, es esa la aproximación que siguió el Code civil français de 1804 [en el Libro III, Título VIII, el art. 1708, que señala las clases de louage, opone el louage de choses al louage d'ouvrage; y el 1710, define louage d'ouvrage; y en la regulación contenida Capítulo III, bajo el título Du louage d'ouvrage et d'industrie, art. 1779 y ss.], y que aún conserva. $\mathrm{Y}$ es, por la recepción de dicho Código, la que, en idénticos términos, recogieron los códigos civiles de Bélgica y Luxemburgo. Es también la forma de regulación adoptada por aquellos códigos que, en esta materia, siguieron de cerca al modelo francés, como son el Código civil italiano de 1865 [en el Libro III, Título IX, en los arts. 1568 y 1570 (que corresponden a los arts. 1708 y 1710 Code) y en la regulación contenida en el Capítulo III, Della locazione delle opere, art. 1627 y ss.], y el Código civil español de 1889, todavía en vigor [en el Libro IV, Título VI, en los arts. 1542 y 1544 , que

$4 \quad$ En este sentido, Kaser: "es un contrato unitario, y este carácter se mantiene a pesar de la variedad de relaciones que puede constituir su contenido” [Kaser, M. (1968) Derecho romano privado, versión de la 5 a $^{\mathrm{a}}$ ed. alemana por José Santa Cruz Teijeiro, Madrid: Reus, p. 197]. En el mismo sentido Guzmán Brito, para quien la misma denominación "locatio conductio" pone de relieve que, para los romanos, todos los supuestos, incluida la llamada locatio conductio operis, tienen como elemento común la existencia de la "colocación" de algo a otro, que la "conduce" o "lleva" para hacer algo [Guzmán Brito, A. (1996) Derecho

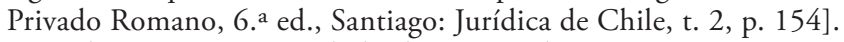

5 Esta idea no es romana, de hecho, es mucho más antigua. Hay evidencia de que en Mesopotamia, en el período neobabilonio (siglos VII-VI AC) los contratos de trabajo contenían usualmente la expresión "colocarse a disposición de (nombre del empleador)" e "ir bajo la dirección de (nombre del empleador)", en una comprensión similar a la del Derecho romano [Silver, M. (1995) Economic Structures of Antiquity, Westport: Greenwood Publishing Group, p. 136]. 
corresponden a los arts. 1708 y 1710 Code; y la regulación contenida en el Capítulo III, Arrendamiento de obras y servicios, art. 1583 y ss.). En el ámbito latinoamericano, la concepción romana unitaria del arrendamiento fue recogida, por ejemplo, por el Código civil chileno (Libro IV, Título XXVI, Del contrato de arrendamiento, art. 1915 y ss.) y también en otros en que aquel tuvo importante influencia, como el colombiano (art. 1793 y ss.), el del Salvador (art. 1703 y ss.), o el de Ecuador (art. 1856 y ss.). También se recogió esta aproximación en el Código civil uruguayo (art. 1776 y ss.) y en el argentino (Libro II, Título VI, art. 1493 y ss.).

El objetivo de este trabajo es el estudio de algunos aspectos centrales del modelo romano de la locatio conductio, con el fin de poder sentar algunas bases que permitan valorar, posteriormente, el grado de influencia que ese modelo romano de la locatio conductio tuvo en las codificaciones civiles decimonónicas a la hora de regular los contratos que tienen por objeto la prestación de un servicio. Por tanto, este trabajo no pretende dar cuenta de la forma en que se produjo la recepción de la concepción unitaria romana del arrendamiento en las mentadas codificaciones civiles. Este trabajo constituye solo un primer paso -necesario- para poder dar cuenta de la forma en que históricamente se ha construido la categoría de los contratos de servicio en el Derecho continental.

Tres son los aspectos que se abordan en este trabajo. Un primer aspecto a tratar es el de la delimitación externa de la locatio conductio frente a otros tipos contractuales. Y es que, el amplio abanico de posibles objetos que podía tener la locatio conductio no implica que todas las relaciones jurídicas que tuvieran por objeto un "servicio" o una "actividad" quedasen bajo su alero. Un segundo aspecto que interesa particularmente es, saber si puede decirse que, en el Derecho romano, hay un modelo general de regulación de los "contratos de servicio" (en un sentido amplio). Dicho de otro modo, interesa determinar si es posible, a partir de algunas notas sustantivas, caracterizar el modelo romano de la contratación remunerada de servicios. Ahora bien, tal tarea no es sencilla, pues se requiere determinar, previamente, si es posible distinguir "modalidades" o "subtipos" de locatio conductio, lo que nos lleva al conocido problema de la unidad o tripartición de la locatio conductio.

Este trabajo, en consecuencia, se estructura en tres partes. La primera trata de la delimitación externa del tipo locatio conductio. La segunda, trata del problema de su la división interna del tipo (la cuestión de la unidad o tripartición), y la tercera, da cuenta de los principales aspectos sustantivos del modelo romano de la contratación de servicios. 


\section{1) Primera CUeSTión. La delimitación EXTERNa Del TIPO locatio CONDUCTIO FRENTE A OTROS CONTRATOS (DEPÓSITO, MANDATO Y COMPRAVENTA)}

Los elementos característicos de la locatio conductio, que permiten distinguirla de otros contratos en los que una parte también ha de realizar alguna actividad en favor de la otra, son dos. Uno, su carácter esencialmente oneroso. El otro, la necesidad de que una de las partes entregue a la otra algo, sobre lo que esta otra parte ha de realizar su actividad.

\section{1.) EL CARÁCTER ESENCIALMENTE ONEROSO DE LA LOCATIO CONDUCTIO}

La locatio conductio es un contrato esencialmente oneroso: debe existir una contraprestación o precio, llamada generalmente merces $^{6}$, que debe consistir en dinero ${ }^{7}$. Conviene destacar que esta merces la paga quien se beneficia de la "colocación", de forma que, según el caso, puede ser de cargo del locator o del conductor.

Esta última precisión es importante, ya que, debido a que la designación de las partes en la locatio conductio no está vinculada a la obligación del pago del precio, la utilización de voces modernas, como son "arrendatario" y "arrendador", no es adecuada para describir y analizar el rol de las partes en la locatio conductio, y más bien puede generar confusión, puesto que las voces "arrendatario" y "arrendador"

6 Gayo 3.142: "El arrendamiento o locación se rige por reglas similares, ya que a menos que se fije precio, no se considera que se haya contraído" ["Locatio autem et conductio similibus regulis constituitur; nisi enim merces certa statua sit, non uidetur locatio et conductio contrahi”; destacado añadido]. Como sostiene Martínez Vela, las fuentes también utilizan otros términos, como pensio, manupretium, o venctura, pero merces es el más común. Por otro lado, el carácter esencialmente oneroso de la locatio conductio no impedía que, posteriormente, las partes pudieran acordar o disponer su condonación [Martínez Vela, J. A. (2010) "Breves reflexiones sobre la merces en el contrato de locatio conductio", Revista General de Derecho romano, n. 14, pp. 2-6].

7 Por ello, si se da como merces algo distinto de dinero, o se compromete a cambio un hecho, entonces el contrato sería un contrato innominado, y en consecuencia, no habría acción civil [Michon, L. (1890) Droit romain: du louage d'ouvrage, locatio conductio operis faciendi. Droit français: des enquêtes parlamentaires, étude de Législation comparée. Thése pour le doctorat, Paris: Arthur Rousseau, éditeur, p. 54 y ss.]. La afirmación se apoya en Gayo 3.144 ("Se pregunta asimismo si hay locación en el caso de que yo te diera a ti una cosa para usarla, y a la vez recibiera yo otra de ti"; Inst. 3.24.2); texto que debe leerse en relación con Gayo 3.142 (que establece que las reglas de la locatio conductio son las mismas que las de la compraventa, véase nota anterior) y Gayo 3:141 ("El precio debe consistir en una cantidad determinada de dinero. Se cuestiona si realmente puede consistir también en otras cosas [...]”). Según los autores, la única excepción a esta regla, de que la contraprestación en la locatio conductio debía ser una suma de dinero, fue la llamada colonia partiaria, por la cual el conductor prometía, como remuneración, parte de los frutos de la cosecha [Schulz (1969) 522; Girard (1906) 568]. 
designan, respectivamente, a la parte que paga y a la parte que recibe el precio o "renta" 8 .

El elemento de la onerosidad juega, como se ha señalado, un rol relevante en la delimitación externa del tipo de la locatio conductio, respecto de otros contratos? ${ }^{9}$. En lo que aquí interesa, lo juega particularmente respecto de aquellos contratos que también tienen por objeto una "actividad". En efecto, la onerosidad permite distinguir la locatio conductio del contrato de depósito y del contrato mandato.

\subsection{1.) La locatio conductio y el contrato de depositum (depósito)}

A diferencia de la locatio conductio, contrato esencialmente oneroso, el de depósito es un contrato esencialmente gratuito. Así, si la obligación de cuidado y vigilancia de una cosa, por tiempo determinado, es obligación remunerada, habrá locatio conductio y no depósito ${ }^{10}$.

Ahora bien, lo anterior puede afirmarse con claridad, en todo caso, solo en relación con el Derecho romano clásico. Pues, ya en la compilación justinianea se advierte una contradicción: a la vez que se recoge el

8 Sobre este punto, conviene señalar que, aun cuando, posteriormente, en el Derecho intermedio español se utilizó también la voz "logar" (que es derivada de "locatio"), se terminó imponiendo la de "arrendamiento", voz que no se construye en consideración de la cosa que se "coloca" sino en consideración del beneficio que se obtiene como contrapartida, la "renta" (del latín, reddĭta), y consecuentemente, ello define los roles: es "arrendador" quien recibe la renta, y "arrendatario" quien la paga [Guzmán (1996) 154]. También la codificación francesa rompió con esta tradición terminológica de calificar a las partes del contrato según cuál es la parte que "coloca" algo, aun cuando se conserva la influencia lingüística en las voces modernas (el contrato de arrendamiento se denomina louage; y las partes locateur, y locataire). En efecto, desde la codificación civil se entiende que lo que califica a las partes en este contrato (louage) no es quién "coloca”, sino la determinación de quién debe pagar el precio, siendo siempre locataire quien lo paga, y locateur, quien lo recibe.

9 El carácter esencialmente oneroso de la locatio conductio también es el elemento que permite -como en la actualidad- distinguir este contrato del contrato de comodato, cuando la prestación de la locatio conductio consiste en la entrega de una cosa para que otro la use y disfrute por un tiempo ["Una cosa ha sido dada propiamente en comodato, si no habiéndose aceptado o establecido ninguna retribución, se te dio la cosa para usarla: de otro modo, mediando retribución, se estima que se te arrendó el uso de la cosa; pues el comodato debe ser gratuito" (Inst. 3.9.2)].

$10 \quad$ Inst. 3.26.13: "Ha de saberse, por último, que el mandato, si no fuere gratuito, cae en otra forma de negocio; porque habiéndose fijado estipendio, comienza á ser arrendamiento: y para hablar en general, en aquellos casos en que, habiéndose aceptado un encargo sin retribución, se celebra un contrato de mandato o de depósito, en estos mismos casos, mediando retribución, se entiende que se hace un arrendamiento" (destacado añadido). No es fácil, sin embargo, determinar si, en la lógica de la tricotomía de la locatio conductio habría de considerarse locatio conductio operarum o locatio conductio operis (sobre la cuestión de la unidad o tricotomía, véase infra [11] y ss.). Sin duda la solución depende de en cuál de las obligaciones se pone el acento: si en la de cuidado, sería operarum; si en cambio, en la de restitución, sería operis [como afirman, por ejemplo, Dazza Martínez, J./Rodríguez Ennes, L. (2009) Instituciones de Derecho Privado Romano, Valencia: Tirant lo Blanch, p. 347]. 
principio del carácter esencialmente gratuito del depósito, ciertos pasajes parecen admitir el "depósito remunerado"11.

\subsection{2.) La locatio conductio y el contrato de mandatum (mandato)}

Al igual que el depósito, el contrato romano de mandato es un contrato esencialmente gratuito: según las fuentes, si se conviene una remuneración a favor del mandatario, el contrato degenera en locatio conductio $^{12}$

No obstante lo dicho, hay que tener presente que la onerosidad esencial de la locatio conductio sirve como elemento de delimitación conceptual, respecto del mandato, solo en aquellos casos en los que la prestación característica de ambos contratos coincide sustancialmente. Esta precisión es importante, porque, como se muestra de inmediato, en la doctrina romanista no parece ser un punto pacífico el que el único criterio para diferenciar estos dos contratos sea la onerosidad o gratuidad esencial que los caracteriza.

Entre quienes sugieren que ambos contratos (locatio conductio y mandato) tienen la misma prestación característica, y que la única diferencia que hay entre ellos es la existencia de una remuneración, se encuentra, por ejemplo, GIRARD, quien sostiene que el carácter esencialmente gratuito del mandato permite inferir que, a la inversa, "cualquier servicio que a cambio de una merces constituiría un arrendamiento, es objeto de mandato cuando el mismo se encarga gratuitamente"13.

El problema de admitir tal posición es que resulta muy difícil justificar la existencia independiente de los contratos de locatio conductio y

11 Martín Santisteban señala que la doctrina mayoritaria entiende que, si el dinero no se hubiera recibido en concepto de salario sino de premio, honorario o indemnización, el acuerdo celebrado entre las partes seguiría siendo un depósito [Martín Santisteban, S. (2004) "Responsabilidad en el contrato de depósito, su génesis histórica”, Anuario de Derecho civil, v. 57, p. 136]. Metro señala que en el Derecho justinianeo la desnaturalización del depósito en locatio conductio, en caso de mediar una merces parece no ser una consecuencia necesaria, "creando" el depósito remunerado. El autor concluye, de un análisis de los textos, que "en el derecho justinianeo decayó el principio de la absoluta gratuidad del depósito, elemento en cambio fundamental para los clásicos y común, por otra parte, también a otros contratos. Surge entonces una nueva concepción justinianea que recibe la categoría de contratos reales, pero introduce importantes excepciones que destruyen la tipicidad de las figuras contractuales individualmente consideradas" [Metro, A. (2008) "El depósito retribuido desde el Derecho romano hasta los modernos códigos", Revista General de Derecho Romano, n. 10, pp. 7-9].

12 D. 17.1.1.4 ("Es nulo el mandato, si no es gratuito, porque trae su origen de la oficiosidad y de la amistad; luego la retribución es contraria a la oficiosidad, porque interviniendo dinero, la cosa tira más bien a locación y a conducción”) y también Inst. 3.26.13 (supra nota 10).

13 Girard (1906) 581-582. El autor agrega que "le fait dont une des parties est chargée" puede ser la administración general de un patrimonio o la ejecución de un acto determinado, y que, en este último caso, puede ser tanto un acto material, como la limpieza de unos vestidos o la exposición de un alegato, como un acto jurídico, como garantizar una deuda o la compra de un bien por su cuenta. 
de mandato, porque hubiera bastado admitir la contratación de servicios gratuitos (en el marco de la locatio conductio), o bien la posibilidad de un mandato remunerado, para que la distinción entre ambos contratos hubiera desaparecido. Y sin embargo, la diversa calificación contractual se mantiene incluso una vez que se admite la posibilidad de pactar una remuneración en el mandato ${ }^{14}$.

Lo cierto es que la justificación de la distinción entre la locatio conductio y el mandato parece obedecer, más bien, a consideraciones sociales: los servicios materiales (manuales) tenían una baja consideración social, a diferencia de los servicios inmateriales o intelectuales, que podían ser prestados por hombres libres y que, por la consideración social que merecían quienes los prestaban, no podían ser remunerados. En consecuencia, ciertos "servicios", como los del abogado, constituían necesariamente mandatum, y no locatio conductio ${ }^{15}$.

Por otro lado, se ha sostenido que el mandato podía tener como objeto la prestación de ciertos servicios que en ningún caso podrían encajar en la locatio conductio, como la realización de actos jurídicos y en general, la administración de un patrimonio ${ }^{16}$. Se ha sostenido, además, que "los trabajos materiales gratuitos no constituyen mandato, sino que quedan fuera de toda consideración jurídica" ${ }^{17}$.

\section{2.) LA NECESIDAD EN LA LOCATIO CONDUCTIO DE QUE SE ENTREGUE UNA COSA: DISTINCIÓN RESPECTO DE LA COMPRAVENTA}

Como se ha indicado, la onerosidad esencial de la locatio conductio no es el único elemento relevante en lo que se refiere a su delimitación externa como tipo contractual. La caracterización genérica del tipo locatio conductio, sobre la base de que exige siempre la "colocación" de una cosa, constituye el otro elemento de delimitación conceptual externa, que juega

14 GirARD (1906) 581-582. El autor sostiene que, una vez que fue admitida la contraprestación en el mandato, este contrato debió haber quedado comprendido en la locatio conductio, y la contraprestación debió calificarse como merces, pero que, en cambio, se le dio otro nombre distinto a la contraprestación (honorarium), y se permitió únicamente reclamar su pago por vía extraordinaria. Así, el honorarium del mandato se considera más bien una donación remuneratoria que un pago equivalente al servicio recibido [véase: Schulz (1969) 530-531; D'Ors, Á. (1977) Derecho privado romano, 3. a ed., Navarra: Eunsa, p. 516; Alemán Monterreal, A. M. (1996) El arrendamiento de servicios en Derecho Romano, Almería: Editorial Universidad de Almería, pp. 57-68, y Martínez Vela (2010) 7-9].

15 Alemán Monterreal (1996) 57-68; y Zimmermann, R. (1990) The law of obligations. Roman foundations of the civilian tradition, $1 .^{a}$ ed. (reimpresión de 1992), Cape Town: Juta and Co., pp. 388-391.

16 Michon (1890) 53; y D'Ors (1977) 516-518. En todo caso, conviene recordar que el mandato romano no es una forma de representación jurídica. Los actos del mandatario no obligan al mandante en ninguna forma y los contratos celebrados por aquel lo son siempre a nombre propio.

$17 \quad$ Véase D’Ors (1977) 518 
un rol en el caso en el que, a cambio de un precio, la obligación que asume el conductor consista en manipular (transformar, modificar, procesar, etc.) algo que ha recibido y que posteriormente debe restituir.

En este sentido, la determinación de quién es el que aporta el material necesario para la confección de un bien, opera como criterio de distinción entre la locatio conductio y el contrato de compraventa. Así, si es el artífice quien suministra la parte principal de la materia con la cual debe confeccionarse el objeto, se entiende que el contrato es compraventa (y el artífice no es, por tanto, conductor sino vendedor) ${ }^{18}$. En caso contrario, o sea, si la parte que encarga la confección del bien es quien suministra la materia, el contrato es calificado de locatio conductio.

Ahora bien, hay que tener presente que la calificación de este supuesto como locatio conductio supone admitir que la relación entre locator y conductor queda fuera del ámbito de la specificatio, cuestión que, a partir de los elementos que ofrecen las fuentes, es discutible. En este sentido, SToop (1998) ofrece evidencia de un debate entre los juristas romanos: mientras que para los sabinianos el hecho de que los materiales se hayan transformado en una nova res no afecta al derecho de dominio (y, por tanto, es posible decir que el objeto producido por el artífice pertenece en todo momento al que ha encargado la obra, suministrando los materiales), el punto de vista de los proculeyanos era que, por el trabajo de transformación, el artífice se hace dueño de la nova res, y por tanto, al hacer entrega ("restitución”) de este bien al que lo encargó, el artífice está en la posición de "vendedor"19.

El hecho de que, en la locatio conductio, deba "colocarse" algo, determina y permite explicar el que, el contrato por el cual una parte encarga la construcción de un inmueble, aun cuando el constructor sea quien ponga todos los materiales necesarios, sea considerado siempre locatio conductio y no compraventa, desde que el suelo sobre el que se construye -que es de propiedad del locator- se mira como la materia principal ${ }^{20}$.

18 Gayo 3.147 (Inst. 3.24.4): "Si yo conviniera con un orfebre que me hiciera unos anillos con oro suyo de un peso y forma determinados, y recibiera, por ejemplo, doscientos denarios: ¿se contrae compraventa o locación? Casio dice que, por el trabajo, hay compraventa; por la materia, locación, si bien, la mayoría opinó que se contraía compraventa. Mas si yo le diera oro mío y además una paga por el trabajo realizado, se admite que hay locación". La solución parece razonable, porque no se entiende por qué habría que distinguir este caso -la compra de un objeto que debe realizarse- del caso en que el objeto hubiera sido ya confeccionado [MichON (1890) 51].

19 Stoop, B. C. (1998) "Non solet locatio dominium mutare. Some remarks on specificatio in classical roman law", Tijdschrift voor Rechtsgeschiedenis, v. 66, particularmente p. 17 y ss.

20 D. 19.2.22.2: "Cuando arriendo la edificación de una casa, de modo que el arrendatario lo haga todo a su costa, me transmite la propiedad de todo y, no obstante, hay locación, pues el que hace la obra arrienda su trabajo es decir, el tener que hacerla" ["Quum insulam aedi- 
La distinción entre la compraventa y la locatio conductio es importante, puesto que, sin perjuicio de que existen similitudes entre estos dos contratos $^{21}$, hay diferencias en materia de responsabilidad y riesgos ${ }^{22}$.

\section{2) LA DIVISIÓN INTERNA DEL TIPO LOCATIO CONDUCTIO (EL PROBLEMA DE LA UNIDAD O TRIPARTICIÓN)}

Como inicialmente se apuntó, la pluralidad de objetos, que caracteriza al contrato de locatio conductio, no solo plantea los mentados problemas de delimitación externa del tipo contractual (en relación con los contratos de depósito, de mandato y de compraventa), sino que, además, ha dado lugar a la conocida cuestión sobre la unidad o tripartición de la locatio conductio. Es este un debate académico sobre la historicidad y potencial utilidad didáctica de la división generalizada de la locatio conductio en tres "modalidades" o "subtipos" (la llamada teoría de la tripartición), y que son las siguientes: la locatio conductio rei (arrendamiento de cosa), la locatio conductio operarum (arrendamiento "de servicios") y la locatio conductio operis (arrendamiento "de obra").

Siendo, propiamente, un debate de la doctrina romanista, una aproximación al problema de la unidad o tripartición de la locatio conductio interesa en el marco de la finalidad de este trabajo, al menos por los dos siguientes aspectos: $i$ ) ayuda a comprender los motivos que llevaron a los romanos a agrupar bajo un mismo tipo contractual relaciones jurídicoeconómicas que hoy nos resultan claramente distinguibles; ii) resulta útil a la hora de entender y justificar los "subtipos" de arrendamiento que el Code civil français de 1804 contempló, y en consecuencia, también permite entender los "subtipos" de arrendamiento que recogieron otros códigos civiles decimonónicos, que le utilizaron como modelo. Adicionalmente, este estudio ofrece las bases para valorar el alcance de la asimilación jurisprudencial y doctrinal, que puede observarse en algunos ordenamientos jurídicos entre la locatio conductio operis y el "contrato de obra", y de

ficandam loco, ut sua impensa conductor omnia faciat, proprietatem quidem eorum ad me transfert et tamen locatio est: locat enim artifex operam suam, id est faciendi necessitatem"; destacado ańadido].

21 Véase supra nota 1.

22 Sobre todo una vez que la responsabilidad por vicios ocultos se vuelve la regla general respecto de todas las compraventas, ya que el conductor, en el marco de la locatio conductio, responde solo por impericia y culpa, y no por la calidad de los materiales si no ha sido él quien los ha aportado (véase infra [24]). Debido precisamente a lo que se acaba de decir, Stoop sostiene que la calificación de los contratos para la confección de bienes a partir de materiales ajenos como locatio conductio o como compraventa (si se considera que quedan cubiertos por el principio de la specificatio) tuvo que ser un problema importante en la práctica [SToop (1998) 22-23]. 
la locatio conductio operarum y el "contrato de servicios", como ocurre en el Derecho espańol.

\section{1.) El PROBLEMA DE LA UNIDAD O TRIPARTICIÓN DE LA LOCATIO CONDUCTIO: LAS DISTINTAS TESIS DE LOS AUTORES}

\subsection{1.) La tesis unitaria de la locatio conductio}

Aun cuando suele admitirse que es posible hallar antecedentes de la tesis unitaria de la locatio conductio en alguna doctrina del siglo XIX ${ }^{23}$, hay consenso en que fue Arangio-Ruiz (en 1921) el primero que explícitamente rechazó que los romanos conocieran la tripartición de la locatio conductio $^{24}$. ArANGIO-RuIZ asume, claramente, una postura "rupturista" con la que él denomina "tesis dominante" 25.

23 Como antecedente de la visión unitaria propuesta por Arangio-Ruiz en 1921 (de la que se da cuenta de inmediato en el cuerpo del texto) suele citarse la tesis de Bechmann. Este autor, en la segunda mitad del siglo XIX, había intentado reducir el origen de las tres especies de locatio conductio al esquema unitario de la locatio rei, basándose en que en los tres casos el objeto del contrato era una res (cosa): en la locatio conductio operarum, al menos en el origen, el objeto del contrato no es el trabajo sino la entrega de un esclavo (y por tanto, es esencialmente un arrendamiento de cosa); y en el caso de la locatio conductio operis, el contrato solo se considera arrendamiento cuando el locator es quien entrega las materias para la construcción (en caso contrario, como se ha visto, se consideraba como una compraventa) de modo que es también un arrendamiento de cosa, que el conductor debía restituir transformada, y pagando una cifra simbólica: "nummus unus" [sobre este punto véase Fiori, R. (1999) La definizione della "Locatio conductio": Giurisprudenza romana e tradizione romanistica, Napoles: Jovene, pp. 1-2, en nota; y Brasiello, U. (1927) "L'unitarietà del concetto di locazione in diritto romano", Rivista Italiana per le Scienze Giuridiche, enero-marzo, p. 537)]. Así, para Bechmann, la única diferencia existente entre los diversos "tipos" de locatio conductio estaría en quién debe el precio: en la locatio conductio operis el pago del precio sería de cargo del locator, mediante una lex contractus que tendría como efecto una inversión respecto del contratante que se beneficia de la cosa y que debe pagar por ello [véase AmIRANTe, L. (1959) "Ricerche in tema di locazione", Bulletino del'Istituto di Diritto Romano, p. 10, en nota]. La debilidad de este punto fue puesta de manifiesto por Pernice, pues ello implicaría admitir una lex particular dirigida a mutar el negocio en sentido contrario, lo que no parece posible [sobre este punto, véase Brasiello (1927) 554 y ss.; y Amirante (1959) 10].

24 Atribuyen esta primacía temporal a Arangio-Ruiz, entre otros autores: Brasiello (1927) 535; Amirante (1959) 9; Alzon, C. (1963) "Réflexions sur l'histoire de la locatio-conductio", Revue Historique de Droit Français et Étranger, p. 553; Pinna Parpaglia, P. (1983) Vitia ex ipsa re aspetti della locazione in diritto romano, Milán: Giuffrè p. 135; Pókecz Kovács, A. (2001) "Quelques observations sur la division de la locatio conductio", Studia Iuridica Auctoritate Universitatis Pecs Publicata, v. 127, p. 217.

25 Arangio-Ruiz, V. (1942), Instituzioni di Diritto Romano, 6. a ed. inalterada, Nápoles: Jovene, p. 354 y ss. En efecto, Arangio-Ruiz, tras definir la locatio conductio como "un contratto consensuale, in forza del quale una delle parti (locatore) si obbliga a mettere nella materiale disposizione dell'altra (conduttore) una certa cosa, che questa si obbliga a restituire dopo averla goduta per un certo tempo o dopo averla manipolata o trasportata nel modo convenuto: secondo le varie ipotesi, spetta al locatore o al conduttore il corrispettivo di una somma di danaro, detta mercede (merces)", expresa que "[l]a definizione che diamo non 
Sin embargo, el estudio realizado en esta investigación, de la doctrina romanista del siglo XIX sobre este punto, impide identificar la tesis de la tripartición de la locatio conductio como marcadamente dominante en ese período. Es cierto que en algunos importantes textos de Derecho romano del siglo XIX es posible hallar el esquema tripartito de la locatio conductio ${ }^{26}$, pero, en otros textos, la división es simplemente bipartita, oponiendo el "arrendamiento de cosas", al "arrendamiento de obras y servicios" 27 (que algunos subdividen, a su vez, en locatio conductio operis y locatio conductio operarum $)^{28}$. Por otra parte, los textos en los que se encuentran

corrisponde alla dottrina dominante; secondo la quale il nome della locazione-conduzione è comune a tre contratti diversi” (pp. 354-355; cursivas añadidas).

Por ejemplo, Ortolan. Este autor explica que el objeto del arrendamiento puede ser de diversa naturaleza, acogiendo la tripartición de la locatio conductio: hay locación de cosa (res), de trabajos o servicios (operae), y de una obra cualquiera (opus), agregando que en la locación de trabajos o servicios, éstos deben pagarse en proporción a su duración; mientras que por las obras se paga un precio determinado [OrTolan, M. (1847) Explicación histórica de las instituciones del emperador Justiniano, traducido de la tercera edición por Pérez de Anaya, Madrid: La Ilustración, t. 2, pp. 353-370). También Heineccio, quien señala que la locación puede ser de cosas, de servicios ("cuando se prestan los que son liberales") o de obras ("cuando se hace alguna obra por cierta merced"), aunque, para definir la locatio conductio más bien utiliza una división bipartita, pues dice que "es un contrato consensual en que se permite el uso de alguna cosa por tiempo determinado, o se prestan servicios pagando cierto precio" [Heineccio, J. G. (1829) Elementos de Derecho Romano, traducidos y anotados por J. A. S, Madrid: Imprenta de D. Eusebio Aguayo, pp. 289-296].

27 Por ejemplo, Warnkoenig, define la locatio conductio como un contrato en virtud del cual una parte se obliga a ceder el goce de una cosa a la otra durante un tiempo, o a hacer algo para ella por un precio convenido, distinguiendo en forma implícita, luego, dos categorías: por un lado, el contrato de arrendamiento de cosa, y por otro, el arrendamiento de obras o servicios - como una sola categoría - dentro de la cual ubica la construcción de alguna obra, pero que no trata de forma separada [Warnkoenig, L. A. (1827) Éléments de droit romain privé (traduit du latin sur la seconde edition) Paris: Chez Deschamps, Libraire, p. 181 y ss.]. También distingue solo dos tipos Phillimore: "hay dos objetos principales de la locatio conductio. Primero, la locatio conductio rerum. En segundo lugar, la locatio conductio operarum" [Phillimore, J. G. (1863) Private Law among the romans from the pandects, London and Cambridge: Macmillan and Co., p. 263].

28 Por ejemplo, Mackeldey, quien enfrenta el arrendamiento de cosas (que llama simplemente locatio et conductio) al alquiler de obra (que denomina locatio conductio operarum). Este, a su vez, lo divide en dos especies: "cuando un criado o artesano promete hacer una obra por cierta prenda" y "cuando alguno promete hacer una obra por una retribución determinada" (locatio conductio operis). La locatio conductio operis sería, como se observa, una modalidad del tipo más amplio, la locatio conductio operarum, pero distinta de la "obra" prometida por el artesano o criado [Mackeldey, F. (1846) Elementos del Derecho Romano, segunda edición, Madrid: Sociedad Literaria y Tipográfica, pp. 236-240]. En el mismo sentido, Petit, quien dentro de la categoría de arrendamiento de servicios, distingue operis y operarum [PETIT, E. (1903) Traité elementaire de Droit romain, 4. ${ }^{a}$ ed., Paris: Arthur Rousseau, éditeur, pp. 384-388]; y May, quien también divide el arrendamiento en dos grandes grupos, de cosas y de industria, y al interior de esta última categoría incorpora la locatio conductio operis y la locatio conductio operarum [MAY, G. (1890) Eléments de Droit romain, Paris: Larouse et Forcel libraires, pp. 320-321]. En los compendios y cursos de Derecho romano editados en España en la primera parte del siglo XIX (generalmente basados en textos extranjeros) tam- 
esas "divisiones" generalmente no tratan por separado esas distintas modalidades de la locatio conductio.

Arangio-Ruiz construyó su teoría unitaria de la locatio conductio a partir de una constatación fundamental: basta la lectura de las líneas que GaYo dedica a la locatio conductio [GAYO 3.142 y ss.], y del título respectivo del Digesto [D. 19.2 ("Locati, conducti")] para concluir que en el pensamiento de los romanos no existía la división tripartita de la locatio conductio. Por ello, el mentado autor define la locatio conductio como un contrato consensual, en virtud del cual una parte (el locator) se obliga a poner a disposición de la otra (el conductor) una cosa determinada, y esta otra parte se obliga a restituírsela después de haberla disfrutado por cierto tiempo o después de haberla manipulado, o transportado, del modo convenido. En la definición de Arangio-Ruiz, el elemento unificador de la locatio conductio es siempre una "cosa" que se entrega y que debe ser restituida, sin que sea relevante a quién corresponde el correlativo pago del precio $^{29}$.

A partir de la tesis de Arangio-Ruiz, varios autores defendieron el carácter unitario de la locatio conductio. El primero de ellos parece ser Brasiello (en 1927) ${ }^{30}$. Este autor señala, expresamente, que toma como punto de partida la tesis de ArAngio-Ruiz, tesis que se propone examinar con una completa revisión de las fuentes ${ }^{31}$. Como resultado de esta investigación, BRASIELlo no solo puede tener por cierta la afirmación hecha por Arangio-Ruiz sobre la inexistencia de la tripartición en GaYo o en el Digesto, sino que agrega dos nuevos argumentos en apoyo de la tesis de la unidad. Por un lado, Brasiello sostiene que el silencio de Gayo sobre este punto es prueba de que la tripartición no era conocida por los romanos, pues en tal caso bien podría GAYO haber hecho la distinción entre diversas clases de locatio conductio (pues, por ejemplo, al hablar del contrato de sociedad, GAYo sí presenta una división entre los diferentes tipos de sociedad). Por otro lado, también como argumento en apoyo de la tesis unitaria, Brasiello agrega que en el edicto del pretor existe una sola fórmula para la actio locati y para la actio conducti, destacando, en este

poco se observa con claridad la mentada tripartición de la locatio conductio. Por ejemplo, en Navarro, R./De Lara, R. J./De Zafra, J. Á. (1842) Curso Completo elemental del Derecho Romano, Madrid: Imprenta del colegio de sordomudos, p. 292 y ss., se sigue la clasificación bipartita de Mackeldey; y la misma división aparece en D. F. C. (1846) Compendio del Derecho Romano, Barcelona: Juan Oliveres, impresor, pp. 158-162.

Arangio-Ruiz (1942) 354 y ss.

Trabajo citado supra nota 23.

Brasiello (1927) 535 
punto, la importancia que tenían las formulas en relación con el Derecho sustantivo $^{32}$.

Otro autor que defendió la tesis unitaria de la locatio conductio fue Olivier-Martin (en I936) ${ }^{33}$. Este autor, luego de un largo análisis de las fuentes, concluye que tanto las obras clásicas como la de los grandes comentaristas, y los textos bizantinos como clásicos, ignoran la existencia de una división tripartita del arrendamiento ${ }^{34}$. Pero además, Olivier-MarTIN propone el que, a su juicio, es el argumento definitivo para rechazar la división tripartita: que es posible reconstruir la génesis de la teoría de la tripartición, ubicándola en la pandectística, en algún momento entre los años 1675 y 1820 , e incluso identifica a quien, a su juicio, es su probable autor, el holandés Johannis VoEt (1647-1713).

Olivier-Martin afirma que, en su opinión, el primero en utilizar la división tripartita de la locatio conductio fue Voet en su obra Commentarius ad Pandectas. De ahí que se trate, según Olivier-Martin, de una división que aparece fuera del ámbito del ius commune, lo que niega la posible influencia de esta teoría en el proceso codificador francés ${ }^{35}$. Ahora bien, sobre esta hipótesis de Olivier-Martin, conviene tener presente que:

i. Como sostuvo Amirante (1959), la investigación de OlivierMartin, "dada la magnitud de la materia examinada, no deja de parecer un poco fragmentaria y sujeta, por lo mismo, a prudente reserva”. Amirante apunta, en este sentido, que también el Derecho canónico y la jurisprudencia rotal habrían contribuido a la formación del contrato de arrendamiento, aspectos no considerados por Olivier-Martin ${ }^{36}$.

ii. Es cierto que la tripartición de la locatio conductio puede apreciarse en la obra de VoET ${ }^{37}$, pero ello no es, necesariamente, prueba de

32 Brasiello (1927) 541. En el resto de su análisis, Brasiello justifica la unidad conceptual de la locatio conductio, sobre la noción de una cosa que se entrega: primero, porque no hay diferencia conceptual entre la locatio conductio operarum y la locatio conductio rei (puesto que se "da" igualmente una cosa, las "operae" son los frutos del trabajo); luego, analizando la locatio conductio operis, sostiene que para los romanos el objeto del contrato no era la actividad -el trabajo- sino la cosa que el locator entrega al conductor, para que haga algo con ella (ibíd., p. 547 y ss.).

33 Olivier-Martin, F. (1936) "Des divisions du Louage en Droit Romain", Revue Historique de Droit Français et Étranger, pp. 419-475.

34 Olivier-Martin (1936) 419-425.

35 Olivier-Martin concluye su estudio, en este punto, con estas palabras: "se trata de una teoría [la de la tripartición de la locatio conductio] que, lejos de ser parte de la auténtica herencia del derecho romano, ha sido inventada en forma bastante oscura, hace poco más de dos siglos, por un jurisconsulto holandés" [(1936) 474].

36 Amirante (1959) 11 (nota 10).

37 Por ejemplo, en su comentario al Libro XIX, Título II, párrafo 33, cuando explica la diferencia entre la locatio conductio operis y la locatio conductio operarum, sobre la base de quién es, en cada caso, el que recibe y paga la merces, en estos términos: "Ac in hâc operis locatio- 
su autoría. Olivier-Martin no señala el año de la primera edición de la obra de Voet (solo indica que utiliza una edición de 1773), pero lo más probable es que dicha obra haya visto la luz por primera vez alrededor de 1698. La investigación que hemos realizado sobre este punto arroja que, por esos mismos ańos, es posible encontrar al menos alguna otra obra en la que se contiene claramente la distinción tripartita de la locatio conductio [así, está presente en E. F. SoMETING, Introductio in Universum Jus (1698) ${ }^{38}$.

Tras Brasiello y Olivier-Martin, otros autores han defendido la tesis unitaria, si bien no siempre construyen su tesis sobre las mismas bases a partir de las cuales la construyó Arangio-Ruiz. Entre estos autores se cuentan, por ejemplo, Amirante (en 1959)39, Pinna Parpaglia (en $1983)^{40}$ y, en forma algo más reciente, FIORI (en 2001) ${ }^{41}$.

ne conductor mercedem accipit, locator dat; cum alioquin in usus aut operarum locatione locator accipiat mercedem, conductor praestet" [Voet, J., (1777) Commentarius ad pandectas, Coloniae Allogrobum, t. 1, p. 679].

38 Someting, al tratar el contrato locatio-conductio (Titulus XXV, pars I), dedica un párrafo (IV) a su división, distinguiendo la locationen rei de la locatio operarum, y luego (p. 649) distingue entre la locatio conductio operarum "en especie" (en sentido estricto) que tiene por objeto solo el trabajo, de la locationem operis, en que el conductor se obliga a una "opus": "Posterior rursus abit in locationem operarum in specie» \& in locationem operis, v. g. aedifici, domûs, \&c. Locatio operurum in specie est, quâ nudae opera alicui locantur. Locatio operis est, qui aliquis certum factum \& opus promittit" [Someting, E. F. (1698) Introductio in Universum Jus, Seriem IV. Librorum \& Titulorum institutionum imperalium, Salisburgi, pp. 648-649].

39 Trabajo citado supra nota 23. Tras su análisis, Amirante termina por afirmar la concepción unitaria de locatio conductio en la jurisprudencia romana, construida a partir de la noción de res locata-conducta y fundada en el interés típico que se pretende tutelar por la jurisprudencia con las acciones actio locati y actio conducti, en cuanto no solo pueden estar dirigidas al pago de la merces, sino también a la restitución o la entrega de la cosa. En su tesis, es la cosa dada que debe ser restituida el elemento unificador de todos los supuestos.

40 Trabajo citado supra nota 24. Este autor, sin embargo, a diferencia de los anteriores autores partidarios de la unidad de la locatio conductio, ya no considera que sea la cosa (que se coloca o que se debe restituir) el elemento a partir del cual se conceptualiza el contrato, sino que es el trabajo el punto común de todos los tipos de locatio conductio: una actividad que alguien se encarga de realizar. Aunque esto resulta más evidente en la locatio conductio operis y la locatio conductio operarum, se presenta como igualmente cierta para la locatio conductio rei, considerando sus orígenes, si se admite, como propone Pinna, localizar el arquetipo del arrendamiento de cosas en el arrendamiento de terrenos de cultivo. Una crítica a esta tesis, aunque más bien formal que de fondo, puede hallarse en Vigneron, R. (1988) "La «Locatio conductio»' secondo i romani”, Labeo, n. 34, pp. 361-372.

41 Trabajo citado supra nota 24. Para este autor, la tipicidad del contrato se halla en la existencia de una relación bilateral en que las obligaciones recíprocas consisten en praestare mercedem y praestare uti frui, Estas prestaciones otorgan una unidad al tipo contractual, que permite diferenciarlo de otros tipos contractuales (se trata de una tipicidad externa), pero, al interior de ese tipo, pueden existir diversas operaciones jurídicas, las que pueden ser relativas a cosas como a personas, y que, cuando se trata de contratos relativos a personas, las fuentes hablan de "operae". A su vez, la prestación de operae puede consistir en poner a disposición del otro contratante el trabajo, sin realizar un opus, o con la obligación de 


\subsection{2.) La tesis tripartita de la locatio conductio}

A diferencia de los anteriores autores, partidarios de la tesis unitaria de la locatio conductio, otros continuaron defendiendo la tesis de la tripartición de la locatio conductio ${ }^{42}$.

Vale la pena destacar, en esta línea, la tesis de Auzon (en 1963) ${ }^{43}$. Alzon no solo pretende justificar la realidad de la tripartición de la locatio conductio en el Derecho romano, sino que, además, partiendo del hecho indiscutible que bajo el contrato de locatio conductio se reunieran relaciones jurídicas muy diversas, se pregunta qué llevó a los romanos a encajar todas esas relaciones jurídico-económicas en un mismo tipo genérico (en la locatio conductio). Su explicación es consecuencia de la reconstrucción histórica de la evolución de la locatio conductio, que el autor califica de particularmente compleja. La conclusión de Alzon es:

"[C]iertamente, todas las formas de locatio conductio (rei, operis, operarum) surgen sucesivamente de la venta y, más especialmente, de la venta de cosas futuras. A pesar de todo, la razones que presiden la creación de estos tres tipos son muy distintas: estrechez de la venta - incapaz de contener las res utenda para la locatio rei; protección insuficiente de las partes contractuales para la locatio operis; deseo de reunir en el mismo tipo contractual todas las relaciones de trabajo, para la locatio operarum" 44 .

Y agrega:

"Ello tiene como resultado la elaboración de un contrato híbrido, sin una caracterización propia. Los romanos prefirieron proceder a mutaciones sucesivas a medida que las necesidades lo requirieron" ${ }^{45}$.

realizar un opus, sea o no bajo la dirección del otro contratante (pp. 361-366). Un resumen del aporte central de Fiori, en relación con la explicación histórica del cambio de paradigma desde la visión bipartita (presente en los autores, desde la Glosa hasta el siglo XIX) al modelo tripartito que -se entiende- se impone en el siglo XIX, puede verse en Ribalta Haro, J. (2012) "La formación de la tripartición locativa: desde el Derecho Romano hasta la codificación civil", en Vaquer, A./Bosch, E./Sánchez, M. P. (coords.) Derecho Europeo de Contratos. Libros II y IV del Marco Común de Referencia, t. 2, Barcelona: Atelier, especialmente, pp. 1101-1104.

Entre los que se encuentran, entre otros, Pernice, Niedermayer y Mayer-Maly. Para un resumen de los principales argumentos de estos autores véase, por ejemplo, Fioni (1999) 5-7; y también Alemán Monterreal (1996) 17-18.

43 Trabajo citado supra nota 24.

44 Alzon (1963) 590.

$45 \quad$ Alzon (1963) p. 591. 


\subsection{3.) La situación actual sobre el problema de la unidad o la tripartición de la locatio conductio}

En la actualidad, la cuestión de la unidad o tripartición de la locatio conductio puede considerarse una cuestión abierta ${ }^{46}$. Por eso mismo, es cuestión que continúa despertando el interés de romanistas e historiadores del Derecho. Prueba de ello son los recientes estudios de Torrent Ruiz (20II)47 y Ribalta Haro (20I 2)48. También se considera que es una cuestión mal planteada ${ }^{49}$.

Por todo lo dicho anteriormente, se comprende que en los tratados y manuales de Derecho romano se adopte una posición más bien neutra en relación con el debate de la unidad o tripartición de la locatio conductio. En este sentido, suele afirmarse que la división tripartita no es propiamente una división romana (aunque a veces se matiza, señalando que sí habría base en las fuentes para que los intérpretes construyeran la teoría de la tripartición de la locatio conductio $)^{50}$. Pero, aun cuando se admite que no se trata propiamente de una división romana, no se renuncia a la división tripartita a efectos expositivos. En efecto, en la mayoría de los textos romanistas se exponen, por separado, las tres "modalidades" o "subtipos" de locatio conductio, los cuales se caracterizan de la forma siguiente: en la locatio conductio rei, el locator entrega una cosa al conductor para que este la use y la disfrute, debiendo restituirla al locator al terminar el contrato; en la locatio conductio operarum, la "cosa" entregada es el "servicio" del propio locator (siendo el conductor quien paga por ellos); finalmente, en la locatio conductio operis, el locator entrega una determinada cosa al

46 FiORI (1999) 10.

47 Torrent Ruiz, A. (2011) "La polémica sobre la tricotomía «res», «operae», «opus» y los orígenes de la «locatio-conductio»", Teoria e Storia del Diritto Privato, n. 4, pp. 1-28.

$48 \quad$ Trabajo citado supra nota 41.

49 En este sentido, Pókecz (2001) 229-230: “[i]l faut souligner que la question qui provoque depuis presqu'un siècle les débats entre les romanistes, c'est à dire unité ou trichotomie, est une question mal posée. Malgrée l'apparence unitaire, qui se manifeste surtout a l'exterieur (par rapport aux autres contrats), on peut diviser de plusieurs points de vue le contenu de la locatio. On a vu que n'ont pas tort ceux qui supposent trois types ou variétés, mais il faut reconnâitre que les termes locatio rei, operarum, operis était de l'invention de la tradition romaniste. D'ailleurs les écoles savantes du moyen age et les codifications actuelles parlent de dualité, trichotomie, même quadripartie et multiplicité, donc l'Europe cultive une religion monolithique où l'esprit de la Sainte Trinité est bien en présence”.

50 En este sentido, KASER: "aunque los romanos mantuvieron la unidad de este contrato, al determinar lo que según la fórmula debe ser el objeto del locare y del conducere [...] ofrecieron antecedentes en que poder basar la tripartición llevada a cabo por el Derecho común y por el moderno" [(1968) 198]. GuZmán BRITo, por su parte, entiende que "la tricotomía escolástica no debe hacer perder de vista la esencial unidad del contrato clásico" y que, "por lo demás, los tres tipos no romanos [...] ni siquiera agotan la variedad de especies que admite el contrato", aunque el autor admite, que "la distinción nominativa entre arrendamiento de un opus y el de unas operae es medieval, aunque con base en las fuentes romanas" [(1996) 155]. 
conductor para que este realice algo con o en ella, debiendo el resultado de dicha actividad (aquí, es el locator quien paga la merces) ${ }^{51}$.

\section{2.) LA DIFERENCIA ENTRE LA LOCATIO CONDUCTIO OPERARUM Y LA LOCATIO CONDUCTIO OPERIS}

Las mismas dificultades que existen para admitir la historicidad de la teoría tripartita de la locatio conductio impiden, naturalmente, ofrecer criterios que permitan conceptualizar, con claridad, cada uno de los tres "subtipos" de la locatio conductio, poniendo de paso, también, en tela de juicio su utilidad didáctica.

En este sentido, mientras que la locatio conductio rei ("arrendamiento de cosas") puede ser caracterizada y diferenciada de las otras dos "modalidades" de locatio conductio con cierta facilidad, trazar la distinción entre la locatio conductio operis y la locatio conductio operarum no resulta tarea fácil, puesto que, en estas dos últimas "modalidades" de locatio conductio, se entiende que la obligación característica consiste en desarrollar una actividad.

El texto del D. 19.2.22.2, transcrito anteriormente (supra nota 20), puede servir para ilustrar el problema de calificación que se plantea, si se asume la posibilidad de distinguir estos dos "subtipos" (locatio conductio operis y locatio conductio operarum). En dicho pasaje del Digesto, la parte que debe construir una casa es considerada, al mismo tiempo, como conductor y locator (es conductor, en cuanto a él se le entrega el suelo para construir; es locator en cuanto "coloca" su trabajo). Es, por tanto, posible preguntarse: ¿qué hay aquí, entonces, locatio conductio operarum o locatio conductio operis?

Conviene apuntar que este pasaje (D. 19.2.22.2), precisamente debido a que considera al constructor tanto conductor como locator, ofrece un nuevo argumento contra la teoría de la tripartición, desde una perspectiva terminológica. En este sentido, Schulz señala que de las fuentes se obtiene, que llamar a quien trabaja "locator" o "conductor" es una diferencia terminológica que carecía de importancia para los juristas clásicos, y que el trabajador podía llamarse a sí mismo locator o conductor según le pareciese. Y agrega que, las consecuencias en materia de responsabilidad y riesgo no están condicionadas al hecho de si el contrato es locatio conductio

51 En este sentido, por ejemplo: Kaser (1968) 197 y ss.; Zimmermann (1990) 351 y ss.; MiQuel, J. (1992), Derecho Privado Romano, Madrid: Marcial Pons, pp. 326-328; GuzMán Brito (1996) 154 y ss.; y Ortega Carrillo de Albornoz, A. (2007) Derecho privado Romano, 2. a ed., Málaga: Ediciones del Genal, 2007, pp. 277-280. Recoge esta clasificación, aunque sin utilizarla en su exposición, Schulz (1969) 518. 
operarum o locatio conductio operis ${ }^{52}$. Luego, desde esta perspectiva, se puede sostener que distinguir entre locatio conductio operarum y locatio conductio operis no solo no parece justificado históricamente, sino que, además, resulta inútil ${ }^{53}$.

En la doctrina romanista se han propuesto diversos criterios para distinguir a estas dos "modalidades" de locatio conductio.

Para algunos, la principal diferencia estaría en que, en la locatio conductio operis, el locator debe entregar al conductor una cosa (una materia) sobre la cual el conductor realiza el trabajo, lo que no ocurre en la locatio conductio operarum ${ }^{54}$.

Para otros, la diferencia entre ambas modalidades de locatio conductio se encontraría en la forma de fijación del precio o remuneración (merces), que en la locatio conductio operarum sería proporcional a la duración de los trabajos, y en la locatio conductio operis sería siempre una suma alzada ${ }^{55}$.

Se ha propuesto también que, frente a la dificultad de distinguir desde un punto de vista objetivo ambas modalidades de locatio conductio, la diferencia es una cuestión práctica: el conductor operis solo se comprome-

52 Schulz (1968) 519-520.

53 En la misma línea de argumentación, en otros pasajes del Digesto ciertas prestaciones son calificadas como "arrendamiento de cosas", a pesar de reunir los elementos necesarios (doctrinalmente) para ser consideradas como locatio conductio operis, como por ejemplo, la limpieza de una vestidos o la confección de vasos o anillos, prestaciones que en D. 19.2.31 se señalan como ejemplo de dos clases de cosas arrendadas (rerum locatarum duo genera ese).

54 En este sentido, para Accarias lo determinante no sería el resultado del trabajo, sino el hecho que la locatio conductio operis exige una entrega previa de la cosa sobre la que se va a trabajar: "vemos que hay un número de casos en los que aquel que realiza el trabajo recibe del propietario la tradición de una cosa determinada, sobre la cual debe, precisamente, ejecutar su trabajo [...] es en estas hipótesis en las que hay locatio operis [...] y al contrario, hay otras hipótesis, que son aquellas que pertenecen a la locatio operarum, en las que el propietario no se despoja de ningún objeto, no hace ninguna tradición" [AcCarias, C. (1874) Précis de Droit Romain, 2. ${ }^{a}$ ed., Paris: A. Cotillon et Cie., t. 2, p. 502]. Así, el autor admite que, en consecuencia, un mismo hecho podría ser, según las circunstancias, objeto de locatio conductio operarum o de locatio conductio operis: por ejemplo, si se encarga el aprendizaje de un esclavo sería locatio conductio operis, pero sería locatio conductio operarum si en vez de un esclavo es un hijo, porque a este no se le puede considerar como una "cosa" que se transfiere (ibíd., p. 502). En un sentido parecido, Ретіт, quien no hace referencia alguna al resultado o la obra como algo característico de la locatio conductio operis [(1903) 388].

Una crítica a los argumentos de Accarias, pueden verse en Michon (1890) 14-16: de las fuentes no se puede desprender que exista locatio conductio operis únicamente cuando hay tradición de una cosa por parte del locator, como ocurre, precisamente, en el caso en que se encarga a un zapatero el aprendizaje de un infante (D. 19.2.13.4) o se encarga el traslado de una mujer a un capitán de barco (D. 19.2.19.7), que se tratan como casos de locatio conductio operis.

55 Olivier-Martin [(1936) 436-438], recogiendo la opinión de Ortolan; pero, en su opinión, el criterio no sería válido, considerando que ya en Javoleno se encuentra un pasaje en que, tratándose de un caso típico de locatio conductio operis, el precio se fija en relación con la duración de la obra. 
tía a realizar un trabajo "si gozaba de un grado de autonomía superior", en relación con el grado de autonomía que tiene el locator operarum ${ }^{56}$.

Sin embargo, y sin que implique negar absolutamente los anteriores criterios de distinción entre la locatio conductio operarum y la locatio conductio operis, para la mayoría de los autores lo característico de la locatio conductio operis es que el conductor debe un opus ${ }^{57}$. Ahora bien, ¿en qué consiste el opus que el conductor debe realizar? La respuesta, también mayoritaria, es que el opus consiste en una obra material. Esta conclusión se apoya, por un lado, en el hecho de que el locator tiene que entregar algo al conductor, que este luego le restituye ${ }^{58}$; y también encuentra apoyo en un pasaje del Digesto que define el opus como "un objeto concluido a partir de una obra realizada", un "corpus perfectum" (D. 50.16.5) 59 .

56 Alemán Monterreal (1996) 53-54. La autora agrega que "las actividades prestadas en una locatio conductio operarum son actividades no cualificadas y de carácter subordinado”. En el mismo sentido, Trigo García, M. ${ }^{a}$ B. (1999) Contratos de servicios. Perspectiva jurídica actual, Granada: Comares, pp. 25-26; y Betancourt, F. (2000) "Normativa y legislación constructiva en la antigüedad y en la alta edad media”, en Graciani, A. (coord.) La técnica de la arquitectura medieval, Sevilla: Universidad de Sevilla, p. 78. Se entiende que esta posición puede encontrar apoyo en D. 19.2.51.1, al menos, en cuanto hay una diferencia en materia de responsabilidad del artífice, que toma como punto de partida el grado de subordinación al dueño de la obra. Se presenta la cuestión de la responsabilidad por la obra defectuosa que se ha arrendado, cuando se ha pactado una remuneración por día de trabajo, y se señala que si es el conductor quien debe probar la bondad de la obra, debe responder si ella resulta defectuosa, "pues lo mismo da que se arriende la obra por un precio único o se arrienden unidades de trabajo, si el arrendatario [conductor] debía entregar la obra terminada”; y se agrega luego, "salvo que se estableciese la retribución por servicios parciales de modo que la obra se fuera haciendo a criterio del dueño, pues, entonces no parece que el arrendatario [conductor] deba responder de la imperfección de la obra”.

57 En este sentido, todos los autores recogidos supra nota 51. En contra, ACCARIAs (véase supra nota 54) y también MAY, quien considera que en ambos casos la obligación es la misma: realizar sus servicios conforme a la convención, la diferencia solo está en quien paga la merces y en la reglas sobre el riesgo [(1890) 147-148].

58 En la medida que la locatio conductio presupone la entrega (colocación) de una cosa para elaborar algo con ella, se concluye que la locatio conductio operis es un arrendamiento "de obra material". El resultado (el opus) supone, primero, un trabajo o un esfuerzo, lo que excluye por ejemplo, que el opus pueda consistir en un "hecho jurídico", como sería, por ejemplo, liberar a un esclavo; segundo, que el hecho a ejecutar se aplique sobre una cosa material (que, como se ha dicho, se supone que ha entregado, al menos parcialmente, el locator al conductor); y tercero, que sea estimable en dinero (pues ya se ha mencionado que, si se trata de ciertos servicios profesionales, no hay locatio conductio, sino mandato) [MichoN (1890) pp. 35-36].

59 Este pasaje del Digesto recoge una cita de Paulo, en la que, a propósito de "opere locato conducto", ofrece la siguiente definición, citando a Labeón: “Con estas palabras «obra arrendada» Labeón dice que se designa a la obra, que los griegos llaman apotélesma, no ergón, esto es, un objeto concluido a partir de una obra realizada" [Opere locato conducto": his verbis Labeo significari ait id opus, quod Graeci $\alpha \pi 0 \tau \varepsilon \lambda \varepsilon \sigma \mu \alpha$ vocant, non $\varepsilon \varrho \gamma \omega \nu$ id est ex opere facto corpus aliquod perfectum]. Algunos autores citan directamente a Labeón, como Grenier, quien define, en consecuencia, a la "locatio conductio operis" como "un contrato en virtud del cual una persona promete a otra un opus perfectum por un precio determinado" [Grenier, J. (1874) Du louage d'ouvrage et d'industrie en droit romain et en droit français, Thèse pour le doctorat, Faculté de Droit de Toulouse: Bergerac: Imprimer du 
No obstante, en la investigación sobre este punto, hemos hallado la opinión divergente de Wubbe (en 1982). Wubbe propone una interpretación distinta del citado pasaje del Digesto (D. 50.16.5): opus es el resultado de un esfuerzo y no el objeto "material" que eventualmente resulte del "opus factum"60. Para este autor, opus significa una actividad (es decir, "un verbo": construir, reparar, limpiar, enseñar) que debe hacerse y que, solo a veces, dará lugar a una cosa material, a un "cuerpo perfecto", pero que ello no es esencial ${ }^{61}$. La interpretación de WubBe, por tanto, ensancha el concepto de opus, sin restringirlo a la construcción o fabricación de algo ${ }^{62}$.

\section{3) AlgunOS ASPECTOS SUSTANTIVOS DEL MODELO ROMANO DE LA CONTRATACIÓN DE SERVICIOS}

\section{1.) DOS ADVERTENCIAS PREVIAS}

Aun admitiendo la utilidad didáctica que puede ofrecer la clasificación tripartita de la locatio conductio, lo primero que hay que tener pre-

Faisand, p. 21]. En el mismo sentido, García Garrido, M. J. (2003) Derecho Privado Romano. Casos, acciones, instituciones, 12. ${ }^{\mathrm{a}}$ ed., Madrid: Ediciones Académicas, p. 497.

Wubbe, F. (1982) "Opus selón la définition de Labeón (D. 50.16.1.5)", Tijdschrift voor Rechtsgeschiedenis, n. 50, pp. 241-251. El argumento principal de este autor es gramatical: la definición contenida al final de la oración ["un objeto concluido a partir de una obra realizada”] sería la definición érgon (ć $\varrho \gamma \omega v)$ no de apotélesma $(\alpha \pi 0 \tau \varepsilon \lambda \varepsilon \sigma \mu \alpha)$, y por tanto, no es la definición de "obra" a la que hay que atender.

61 Wubbe (1982) 246-247. El autor sostiene que la diferencia es sutil y difícil de observar en algunos casos, por ejemplo, en la construcción de un edificio, el edificio mismo no es el "opus", sino el reflejo material del "opus"; aunque es algo más sencilla en otros, por ejemplo, si se trata de trasladar una columna, pues el opus no es la columna "trasladada" sino la suma de operaciones requeridas para obtener el resultado querido; y mucho más clara en los casos en los que no existe ningún soporte material, como dar un curso, o hacer un poema o componer una sinfonía, en la que "la partitura" es un objeto, pero no es "la sinfonía".

62 De hecho, el mismo autor sostiene que mantener la comprensión tradicional -opus como "obra material"- limitaría el contrato de obra a los casos de construcción o fabricación de algo (ibíd., p. 250). De esta forma, "opus facere” significa, primero, ejecutar una tarea o hacer un trabajo, "y por metonimia, comienza a significar luego el resultado material de la acción, esto es, el objeto confeccionado [...] [e]l término opus toma así dos sentidos diferentes pero complementarios: el primero activo, la acción del trabajo, el segundo, pasivo, el producto del trabajo" [EL Bouzidi, S. (1997) "Place et role de la main-d'oeuvre libre dans l'économie rurale á la fin de la République romaine”, Gerión. Revista de Historia antigua, 15, pp. 139-140].

De asumir esta posición, tendríamos que sostener que, consecuentemente, cuando el resultado esperado no sea un objeto físico, ya no podría considerarse necesario que el locator "entregue" algo al conductor, aunque sí será necesaria la entrega de "algo" cuando lo que se espera es un objeto material (pues en caso contrario se consideraría que hay una compraventa). 
sente es que la llamada locatio conductio operarum tenía una importancia más bien marginal en Roma, debido a dos razones: por un lado, porque, como ya se ha apuntado, solo pueden ser objeto de arrendamiento los servicios "inferiores" 63 ; y por otro lado, debido a la disponibilidad de esclavos para realizar tales servicios inferiores, y, por realizarlos esclavos, esos servicios se realizan fuera del marco de una relación contractual ${ }^{64}$. Por ello, no es de extrañar que las reglas que pueden hallarse en las fuentes romanas se refieran básicamente a supuestos que, bajo la lógica de la tripartición de la locatio conductio, pueden ser calificados de locatio conductio operis $^{65}$.

Por otro lado, hay que considerar que, aun cuando pueda intentarse realizar un esbozo del "modelo" de contratación de servicios que resulta de esas reglas contenidas en las fuentes, la abstracción que ello supone choca con el casuismo romano. Por ello, como se verá inmediatamente, es muy discutible sostener la preferencia de una determinada solución, como regla general aplicable a todos los casos.

Solo teniendo en consideración lo que se acaba de decir, es que resulta plausible intentar describir los principales aspectos sustantivos del modelo romano de contratación remunerada de servicios.

\section{2.) LA DESCRIPCIÓN DE LOS PRINCIPALES ASPECTOS SUSTANTIVOS DEL MODELO ROMANO DE CONTRATACIÓN DE SERVICIOS}

\subsection{1.) Las obligaciones del prestador del servicio}

El prestador del servicio debe realizar la tarea encomendada conforme a lo convenido, y en forma oportuna ${ }^{66}$.

63 Véase supra [8] y nota 15.

64 Rodríguez EnNes, L. (2009) "El singular renacimiento de la autonomía de la voluntad y la locatio conductio operarum et operis como consecuencia de la presente depresión económica”, Revista de Derecho de la Pontificia Universidad Católica de Valparaíso, n. 32, pp. 188-190. En el mismo sentido, Zimmermann, quien afirma que la demanda de trabajadores (capacitados y no capacitados) era llenada por esclavos, y que ellos no trabajaban sobre la base de una relación contractual, sino que estaba determinada por la potestas y dominus, y que si el amo deja su esclavo a un tercero, ello constituía locatio conductio rei, no operarum [(1990) 387]. Según este último autor, también se excluían de la locatio conductio los servicios que los liberti prestaban a sus antiguos amos, los cuales no se realizaban en el marco de un contrato, sino sobre la base de una promesa bajo juramento.

65 Desde luego, no es este el lugar para analizar hasta qué punto estas mismas (o parecidas) razones pueden justificar la atención preferente que, siglos más tarde, el Code civil français da al louage d'ouvrage "des devis et des marchés" (arrendamiento de obra por ajuste o precio alzado) en desmedro de otras formas de contratación "de servicios", ni tampoco de la influencia que ello pudo haber tenido en la regulación de otros códigos civiles decimonónicos que siguieron el modelo del Code.

66 García Garrido (2003) 498, con base, por ejemplo, en D. 19.2.51.1 (supra nota 56). Es posible, no obstante, que el conductor se aparte de lo convenido inicialmente, sin responsa- 
Aunque hay bases para sostener que es indiferente si el prestador del servicio realiza el trabajo por sí mismo o se vale de otros para hacerlo, no resulta fácil afirmar que ello sea la regla general ${ }^{67}$. En todo caso, lo que sí es claro es que el prestador del servicio no puede confiar la tarea a otra persona si se ha convenido que él la hará personalmente o si se ha tenido en cuenta su talento pues, en tales casos, la ejecución personal, por el propio el deudor, forma parte del objeto del contrato ${ }^{68}$.

bilidad, en caso que las alteraciones se hubieran introducido por voluntad del locator [ello es lo que desprende de D. 19.2.60.3: "Por pacto expreso se había dado en arrendamiento la construcción de una casa, con la condición de que la aprobación o la desaprobación correspondería al arrendador, o a sus herederos el arrendatario (conductor) había cambiado ciertas cosas en la obra por voluntad del arrendador (locator); respondí, que no parece ciertamente que se hizo la obra según pacto expresado, pero que como se hizo alguna alteración por voluntad del arrendador, debía ser absuelto el arrendatario (conductor)"].

En cuanto a la oportunidad del cumplimiento, es evidente que las partes pueden pactar un plazo para el cumplimiento, pero en todo caso, este plazo no podría ser menor que el necesario para poder concluir la obra, según se desprende de D. 19.2.58.1 ("Se había dicho en la locación de una obra antes de qué día debería hacerse, y después había prometido el arrendatario, si así no se hubiese hecho, tanta cantidad cuanta le hubiese importado al arrendador; opino que se contrae esta obligación por tanto cuanto un buen varón hubiese estimado respecto al espacio de tiempo, porque es claro que se trató esto, que fuese absuelto respecto de aquel tiempo sin el que no pudiera hacerse"). Se trata de una solución lógica, y por ello, era también el criterio de la jurisprudencia romana, por ejemplo, cuando no se había fijado un plazo en la estipulación de construir una casa: la acción no puede ser entablada antes del tiempo necesario para llevar a término la construcción [sobre esto, véase Cuena Boy, F. (2010) Rerum Natura e imposibilidad física de la prestación en el derecho romano, Santiago de Compostela: Andavira, p. 55 y ss.].

67 Hay diversos pasajes en los que se hace referencia a la responsabilidad que pesa sobre el conductor por la culpa de las personas que empleó en la ejecución de la obra (por ejemplo, D. 19.2.25.7: "El que tomó en arriendo el transportar una columna, si mientras se carga, o se transporta, o se descarga, se hubiera roto esta, es responsable de este riesgo, si hubiere acontecido por culpa de él mismo, y de aquellos cuyo trabajo utilizase; mas está exento de culpa, si hizo todo lo que hubiese de haber tenido en cuenta otro cualquiera muy diligente. Lo mismo, por supuesto, entenderemos, también si alguno hubiere tomado en arrendamiento el transportar tinajas o vigas. Y lo mismo puede aplicarse también á las demás cosas"; destacado añadido). Sin embargo, que de ello pueda extraerse una regla general es discutible. En los textos romanos no hay referencia a la posibilidad de subcontratación en los supuestos de locatio conductio operarum, y aunque efectivamente parece admitirse en supuestos calificables como locatio conductio operis, se ha defendido que la subcontratación no estaba generalmente permitida, y que la aproximación de los juristas clásicos era, como en otros aspectos, casuística [Du Plessis, P. (2005) "Subletting and the Roman law of letting and hiring Interpreting C. 4.65.6”, Revue Interrnational de Droits de l'antiquité, n. 52, pp. 135-136). tre los artífices hay gran diferencia de ingenio, de naturaleza, de doctrina, y de ejecución. Y por lo tanto, si alguno hubiere prometido que por él se construiría una nave, o se edificaría una casa, o se haría una fosa, y se trató especialmente esto, que lo hiciera con su propio trabajo, el mismo fiador haciendo el edificio, o cavando la fosa, sin consentirlo el estipulador, no librará al obligado" [(1996) p. 158]. 
Consecuencia de lo dicho, se entiende que la muerte del conductor pone fin al contrato solo excepcionalmente ${ }^{69}$.

En cuanto a la responsabilidad del prestador del servicio (conductor operis), se entiende que este responde de la imperitia; esto es, responde de los daños ocasionados en la ejecución del contrato, ya se deba a su falta de aptitud para la realización de la obra, ya se deba a la culpa de aquellos a quienes empleó en su ejecución ${ }^{70}$.

Mayoritariamente se estima, que el conductor operis respondía, además, por la custodia de las cosas que se le entregaron (lo que incluiría, in-

69 La regla contenida en Inst. 3.24.6 parece absoluta: "Muerto el arrendatario durante el tiempo del arrendamiento, le sucede en él con el mismo título su heredero". Igual en el Cód. 4.65.10: "Desconoces el camino de la verdad, estimando que los herederos del arrendatario no suceden en los arrendamientos, porque, si el arrendamiento es perpetuo, se transmite también a los herederos, y si temporal, durante el tiempo de la locación le incumbe también al heredero la carga del contrato". La regla general, por tanto, es la transmisión de los derechos a los herederos [sobre este punto, véase Du Plessis, P. (2007) "The hereditability of locatio conductio" en Cairns/Du Plessis, Beyond Dogmatics - Law and Society in the Roman World, Edinburgh: Edinburgh University Press, pp. 139-153].

Sin embargo, algunos autores entienden que la muerte del artífice pone fin al contrato de arrendamiento de obras en todo caso, tal como ocurriría con la locatio conductio operarum [así, por ejemplo, Ortolan (1847) t. 2, p. 366; y Mackeldey (1846) 240]. Arangio-Ruiz precisa que esto último solo es así en el Derecho clásico, pero que para el Derecho justinianeo se tiene que considerar, en el caso de la locatio conductio operis, si la habilidad personal del artífice se ha tenido en cuenta en la celebración del contrato, y, solo en caso afirmativo, la muerte extingue la obligación [(1942) 348]. En la investigación realizada sobre este punto, no hemos encontrado, en los textos justinianeos referidos a la locatio conductio, ninguna base para sostener la extinción del contrato por muerte. Posiblemente, sea una regla deducida de los casos de contratos con carácter intuito personae en los que sí se establece expresamente la extinción por muerte, como ocurre en el mandato (Inst. 3.26.10) o en la sociedad (Inst. 3.25.5), partiendo de la base de que es perfectamente posible el pacto por el cual el conductor se obliga a realizar el trabajo personalmente.

70 Sobre la propia culpa, por ejemplo, D. 19.2.9.5: "Celso [...] escribió que la impericia ha de ser tomada como culpa: si alguno tomó en arriendo el apacentar terneros o el remendar o limpiar alguna cosa, debe responder de culpa y aquello en que erró por impericia es culpa, porque, dice, él tomó en arriendo como quien conoce su oficio"; y D. 19.2.13.5: "Si se hubiera dado una piedra preciosa para engastarla ó esculpiría, y se hubiera roto, si verdaderamente esto hubiera sucedido por vicio de la materia, no habrá la acción de locación, y la habrá, si por impericia del artífice. A esta opinión se ha de añadir, a no ser que el artífice hubiera admitido también a su cargo el riesgo; porque entonces aunque esto haya sucedido por vicio de la materia, habrá la acción de locación”. Y en general, sobre la responsabilidad por un resultado defectuoso, D. 19.2.51.1 (supra nota 56). Sobre la responsabilidad por los que están a su servicio, por ejemplo, D. 19.2.25.7 (véase supra nota 67). Para profundizar sobre el origen de la noción de imperitia en el Derecho romano clásico, con un análisis de los diferentes pasajes en que se menciona esta expresión en las fuentes, véase Martin, S. (2001) "Imperitia: the responsability of skilled workers in classical roman law", American Journal of Philology, v. 122, 2001 (1) pp. 107-129. 


\section{cluso, la responsabilidad por robo) ${ }^{71}$. Este punto, sin embargo, es objeto de discusión ${ }^{72}$.}

71 Hay que tener presente que la custodia no aparece en las fuentes como un concepto jurídicamente inequívoco, pues si bien la doctrina romanista mayoritaria ve en ella un estándar de conducta (responder "por" custodia implica responder en todos los casos en que no existe fuerza mayor; una especie de "responsabilidad objetiva"), se ha sostenido igualmente que designa el contenido de la obligación: mantener el objeto a salvo [ZimMERMANn (1990) 193-194, y 398-399].

Como estándar de diligencia, responder por custodia implica que el conductor operis únicamente se libera por fuerza mayor. Esta es la communis opinio, con base en Cód. 4.65.28 ("Consta que en el juicio, así de locación, como de conducción, se comprende el dolo y la custodia, pero no también el accidente a que no se puede oponer resistencia”).

Básicamente, la custodia haría responsable al conductor por cualquier pérdida, siempre que no sea fortuita, incluyendo el robo [Du Plessis, P. (2006) "Between theory and practice: new perspectives on the roman law of letting and hiring", The Cambridge Law Journal, n. 65 , v. 2, pp. 426-427]. Esta es la regla que se desprende de Gayo 3.205: "Si el batanero recibiera unos vestidos para limpiar o arreglar, o el sastre para remendarlos y los perdiera por hurto, él mismo tiene la acción de hurto, no el dueńo, ya que nada interesa a este que la cosa no se haya perdido, porque puede perseguir del batanero o sastre la indemnización mediante la acción de arrendamiento, siempre que estos sean solventes, ya que si no lo son, entonces le compete la acción de hurto al no poder conseguir de ellos la indemnización, puesto que le interesa en este caso conservar la cosa". Y lo mismo se aplica al comodatario, según Gayo 3.206. En el mismo sentido, Miron de l'espinay, quien así lo afirma con base en D. 19.25.7 (supra nota 67) porque al conductor se le exige suma diligencia (el pasaje utiliza la expresión diligentissimus) de modo que el empresario "responde no solamente de la culpa grave, sino también de la leve. Se compara su gestión a la de un buen administrador, tomado en abstracto" [Miron DE L'EsPINAY, A. (1873) Du louage d'ouvrage et industrie en droit romain. Des Entreprises sur devis et marchés en droit français. Thése pour le doctorat, Paris: A. Parent, imprimeur, p. 22].

Algunos autores sostienen que este estándar de diligencia pesaba sobre el conductor en todos los casos, no solo en la locatio conductio operis [en este sentido, por ejemplo, ScHulz: "si resulta cierto que la famosa tricotomía no existe y que la locatio conductio fue un concepto unitario, se sigue de ello que una persona que tomaba en arriendo un animal o un esclavo era responsable por custodia” [(1969) 523]; y también Gómez de la Serna, P., (1863) Curso histórico exegético del derecho romano comparado con el español, 3. ${ }^{\mathrm{a}}$ ed., Madrid: imprenta de la compañía de impresores y libreros del reino, t. 2, pp. 316-317].

En general, sobre la responsabilidad por custodia, véase Puliatri, S. (2009) "Custodiam praestare, para una definición de los límites de la responsabilidad por custodia en el derecho romano", Revista General de Derecho Romano, n. 13, pp. 1-14.

72 Robaye sostiene que la conclusión de que el conductor operis siempre responde por custodia, a partir de la generalización de los casos que se encuentran en las fuentes, es un error. Según este autor, esos supuestos del tintorero y del sastre (que están recogidos en Gayo 3.205 , véase nota anterior) no pueden ser tomados como ejemplos de todo tipo de artífice, porque se trata de casos excepcionales, en los que la responsabilidad por custodia puede explicarse: estos artífices (tintorero y sastre) realizan su trabajo al aire libre, por tanto el riesgo de robo o dańo por parte de terceros es alto, pero como el costo (de evitarlo) es relativamente bajo, es razonable pensar que hayan asumido tal responsabilidad; en otros supuestos, en los que la probabilidad de ocurrencia del riesgo es menor, pero de consecuencias más graves, no es razonable entender que se haya asumido la custodia (como, por ejemplo, tratándose de joyeros); y de ahí el silencio en las fuentes en relación con estos últimos casos [RoBAYE, R. (1991) "Le foulon et le bijoutier à Rome: les risques du métier", Revue Belge de philology et d'histoire, n. 69, v. 1, pp. 131-136]. 
Finalmente, se entiende que el conductor no soporta el riesgo de pérdida o deterioro de los materiales, ni de la obra ya comenzada, en la medida que dicha pérdida o deterioro se deba a fuerza mayor ${ }^{73}$. El conductor solo soporta esos riesgos, en el supuesto de que lo hubiere asumido expresamente $\mathrm{e}^{74}$.

\subsection{2.) Las obligaciones de cliente}

El cliente, por su parte, tiene como obligación principal pagar la merces al prestador del servicio (incluyendo el costo de materiales o los gastos de conservación, en su caso ${ }^{75}$. Además, debe permitir al prestador

73 La regla general se desprende de D. 19.2.36: "La obra que por un tanto se dió en arrendamiento está á riesgo del arrendatario hasta que sea aprobada. Mas la que haya sido tomada en arrendamiento de este modo, para que sea entregada por pies o medidas, solamente está a riesgo del arrendatario mientras no se haya medido; y en uno y en otro caso será del arrendador el daño, si en él hubiere consistido que la obra no se apruebe, o se mida. Pero si por fuerza mayor se hubiere arruinado la obra antes que fuese aprobada, va a riesgo del arrendador, si otra cosa no se hubiera tratado; porque no debe responderse al arrendador de más que de lo que con su propio cuidado y trabajo habría conseguido".

KASER apunta que, antiguamente, el riesgo del precio gravaba siempre al conductor, de forma que si la obra resultaba irrealizable a consecuencia de un caso fortuito, no recibía precio alguno; pero, más tarde, a partir de una doctrina de Sabino, se estableció una distinción: los daños cuya causa están en el empresario, o que afecten su propia capacidad para realizar la obra, son de cargo de este, y pierde el derecho a la remuneración; los daños que proceden de la parte que hizo el encargo (locator) o de la fuerza mayor, son de cargo de éste, y por tanto, dejan subsistente el derecho del conductor a percibir la remuneración, aun cuando la doctrina admite que la locatio conductio operis supone una obligación de hacer indivisible [(1968) 201; y en este sentido, también: D'ors (1977) 551; Girard (1906) 571; y GUZMÁn (1996) 169-170]. Esta distribución de los riesgos tiene base en D. 19.2.61, en el que se pone de cargo del locator el riesgo de destrucción de un canal por vicio del suelo [según Zimmermann, la atribución al locator se justifica porque ello está en su esfera de control [1990) 402-403] y en D. 19.2.59, en el que se pone de cargo del locator y no del empresario, la pérdida de la obra por terremoto. Sobre todo ello, véase también Martin, S. (1986) "The case of the collapsing watercourse: Builder's responsability for damage in classical roman law", Law and History Review, v. 4, n. 2, pp. 423-437.

Por otro lado, la regla sobre distribución del riesgo por pérdida de los materiales es distinta en el caso del arrendamiento de obra llamado "irregular" (locatio conductio irregularis), en la que el conductor se ha hecho dueño de las cosas entregadas, por tratarse de cosas fungibles, y por tanto, el riesgo de su pérdida siempre es del conductor (así se desprende de D. 19.2.31).

74 Así se desprende de D. 19.2.36 (véase nota anterior) y de D. 19.2.13.5 (supra nota 70). La asunción del riesgo del caso fortuito por parte del conductor podría también derivarse, en forma indirecta, por incumplimiento de un acuerdo particular (una lex contractus) como en el caso que aparece en D. 19.2.11.1 (referido a arrendamientos urbanos): "Si se convino que no se encienda fuego, y se hizo, quedará obligado el arrendatario, aunque el incendio haya sido provocado por caso fortuito, porque no debía haber encendido fuego". Sobre la noción y la función de la lex contractus, particularmente en relación con la locatio conductio, véase Du Plessis, P. (2006) "The roman concept of lex contractus," Roman Legal Tradition, n. 3, pp. 79-94.

75 Sobre la obligación de pagar la merces, es importante destacar que el Derecho romano no consideraba el precio fijado en forma previa como una "suma alzada" al que las partes debían 
del servicio realizar el trabajo (por ejemplo, entregando los materiales; permitiendo el acceso al terreno donde se construirá la edificación) y debe recibir y aprobar la obra oportunamente, si esta presenta las cualidades convenidas $^{76}$.

\section{CONCLUSIONES}

Las principales conclusiones de este estudio son las siguientes:

1. Los romanos agruparon bajo un único contrato -la locatio conductio- relaciones jurídicas cuyas finalidades económicas, hoy, nos parecen claramente diferenciadas: una es la cesión remunerada del uso temporal de un bien; la otra, la realización, también remunerada, de una serie de "actividades", "trabajos" o "servicios".

Aunque no resulta fácil desentrañar la justificación de la concepción unitaria de la locatio conductio, me parece que el estudio sobre el problema de la unidad o de la tripartición de la locatio conductio arroja algunas luces, tanto si se considera la perspectiva unitaria (en la tesis de ArangIo-Ruiz, la idea de una "cosa", que debe entregarse, explica teóricamente todos los tipos), como si se considera la perspectiva tripartita (en la tesis de Alzon, por ejemplo, la idea de que una cosa debe entregarse se considera como el punto de partida de una evolución histórica del tipo). Dicho esto, no es prudente aventurar conclusiones sobre la cuestión de la unidad o tripartición de la locatio conductio; pues tal cuestión corresponde a la romanística y supone el manejo de herramientas propias de esa disciplina. Lo que interesa destacar es, que es aquí, en el Derecho romano, donde se encuentra el origen de la concepción unitaria del contrato arrendamiento, concepción unitaria que después recogieron algunos códigos decimonónicos.

2. La finalidad de la exposición sobre el contrato locatio conductio realizada en este trabajo, tiene un carácter instrumental a los objetivos

limitarse; era posible solicitar al juez una rectificación del precio, en caso que el error fuera considerable, debido a que la locatio conductio era un contrato de buena fe [Michon (1890) pp. 61-62]. Además, de D. 19.2.60.4 se desprende que era posible que el locator detuviera los trabajos, si se daba cuenta que se sobrepasaría el presupuesto, pudiendo en tal caso repetir lo dado anticipadamente al conductor ("Te mandé que vieses por cuánto querría edificar una casa de campo; me dijiste que habías visto que por un gasto de doscientos; te di en arrendamiento la obra por cierta retribución, y después averiguo que no podía costar la casa de campo menos de trescientos, pero se te habían dado cien, y habiendo gastado parte de ellos, te prohibí que hicieras la obra; dije, que si hubieres perseverado en hacer la obra, ejercitaré contra ti la acción de locación, para que me restituyas lo restante del dinero").

76 Aplica, en tal caso, la regla de D. 19.2.24: "Si en un pacto de la locación se hubiera expresado, que se apruebe la obra a arbitrio del dueño, se considera lo mismo que si se hubiese expresado el arbitrio de buen varón. Y lo mismo se observa, si se hubiera consignado el arbitrio de otro cualquiera; porque exige la buena fe, que se dé tal arbitraje, cual conviene a un buen varón". 
trazados al comienzo del mismo. Lo que se ha pretendido es sentar unas bases para poder valorar la influencia que tiene este modelo romano de la locatio conductio, en relación con la regulación jurídica de los códigos civiles decimonónicos sobre contratos cuyo objeto es la prestación de servicios (el francés, primero, y los que le siguieron o utilizaron como modelo, y que, como aquel, conservan esta aproximación, como el español, el chileno y el argentino). Y, en este sentido, hay algunos aspectos que resulta interesante destacar, tras finalizar el estudio:

a) El modelo romano para la contratación de "servicios" no puede definirse a partir de la descripción del trabajo, la tarea o la actividad que debe realizar una de las partes. En efecto, una misma clase de actividad (como custodiar una cosa, o realizar de ciertos servicios intelectuales) puede o no ser calificada de locatio conductio, según haya sido prestada en forma remunerada o gratuita. Asimismo, si la actividad del deudor se dirige a la fabricación de un objeto, el contrato puede ser calificado de locatio conductio o de compraventa, según haya sido el acreedor (el cliente o destinatario del servicio) o el propio deudor (el prestador del servicio) quien aporte los materiales a partir de los cuales el objeto se fabrica.

b) La posibilidad de sostener la existencia de diversos "subtipos" dentro de la locatio conductio ha sido, especialmente durante el siglo XX, objeto de una importante discusión en la doctrina científica, discusión que en la actualidad permanece abierta. En mi opinión, el estado actual de este debate sugiere que buscar en el Derecho romano, o en la tradición romanista, una base para diferenciar, con claridad, la prestación de "obras", de la de "servicios", es, cuando menos, muy discutible.

c) Aunque los tratados y manuales de Derecho romano suelen recoger, a efectos expositivos, la teoría de la tripartición de la locatio conductio, da la impresión, que el único modelo de contratación de "servicios" remunerados que puede construirse a partir de las fuentes, corresponde a supuestos que, en la lógica de la tripartición, podrían ser calificados como locatio conductio operis. En el caso del Derecho romano, hay unas razones económicas y socioculturales que permiten explicar la especial atención que los juristas romanos prestaron a la locatio conductio operis en desmedro de la locatio conductio operarum. Como se ha visto, la consideración social negativa de los trabajos "manuales", sumado a la disponibilidad de esclavos para realizarlos, hacen que esta última modalidad de locatio conductio (operarum) tenga una importancia relativa muy escasa.

d) Finalmente, me parece importante volver a recalcar que, pese al esfuerzo que pueda desplegarse para intentar caracterizar el "subtipo" locatio conductio operis, y extraer de él un modelo de contratación de los servicios (en sentido amplio) remunerados, el casuismo romano sugiere evitar (o al menos, proceder con excesiva cautela) en la generalización de reglas que fueron pensadas para distintas clases de actividades. Solo teniendo esto en cuenta, es que puede caracterizarse el contrato romano 
de servicios remunerados: es un contrato en virtud del cual una persona, a cambio de una remuneración, se obliga a realizar una determinada tarea - personalmente, si así lo exige la naturaleza de la tarea, o si así se pactóque debe ejecutar conforme a lo convenido y en forma oportuna, y empleando en ella el cuidado necesario.

\section{BIBLIOGRAFÍA CITADA}

- Accarias, C. (1874) Précis de Droit Romain, 2. ${ }^{\mathrm{a}}$ ed., Paris: A. Cotillon et Cie. (t. 2).

- Alemán Monterreal, A. M. (1996) El arrendamiento de servicios en Derecho Romano, Almería: Editorial Universidad de Almería.

- Alzon, C., (1963) "Reflexions sur l'histoire de la locatio-conductio", Revue Historique de Droit Français et Étranger, pp. 553-591.

- Amirante, "Ricerche in tema di locazione", Bulletino del Istituto di Diritto Romano, n. 1, pp. 9-119.

- Arangio-Ruiz, V. (1942) Instituzioni di Diritto Romano, 6. a ed. inalterada, Nápoles: Jovene.

- Betancourt, F. (2000) "Normativa y legislación constructiva en la antigüedad y en la alta edad media", en Graciani, A. (coord.) La técnica de la arquitectura medieval, Sevilla: Universidad de Sevilla.

- Brasiello, U., (1927) "L'unitarietà del concetto di locazione in diritto romano", Rivista Italiana per le Scienze Giuridiche, pp. 529580 .

- Caillemer, E. (1869) Études sur les antiquités juridiques d'Athènes. Huitième étude: Le contrat de louage a Athènes, Paris: Durand-Thorin

- Cuena Boy, F. (2010) Rerum Natura e imposibilidad física de la prestación en el derecho romano, Santiago de Compostela: Andavira.

- Dazza Martínez, J./Rodríguez Ennes, L. (2009) Instituciones de Derecho Privado Romano, Valencia: Tirant lo Blanch.

- D. F. C (1846) Compendio del Derecho Romano, Barcelona: Juan Oliveres, impresor.

- D’ors, Á. (1977) Derecho privado romano, 3. ${ }^{\mathrm{a}}$ ed., Navarra: EunsA.

- Du Plessis, P. (2005) "Subletting and the Roman law of letting and hiring Interpreting C. 4.65.6", Revue International de Droits de l'antiquité, n. 52, pp. 131-144.

(2006 a) "Between theory and practice: new perspectives on the roman law of letting and hiring", The Cambridge Law Journal, n. 65, 2006, pp. 423-437. (2006 b) "The roman concept of lex contractus," Roman Legal Tradition, n. 3, 2006, pp. 79-94. 
(2007) "The hereditability of locatio conductio" en Cairns/Du Plessis, Beyond Dogmatics - Law and Society in the Roman World, Edinburgh: Edinburgh University Press, pp. 139-153.

- El Bouzidi, S. (1997) 'Place et role de la main-d'oeuvre libre dans l'économie rurale á la fin de la République romaine", Gerión. Revista de Historia Antigua, n. 15, pp. 133-150.

- Fiori, R. (1999) La definizione della "Locatio conductio»: Giurisprudenza romana e tradizione romanistica, Napoles: Jovene

- García del Corral, I. (1889) Cuerpo de Derecho Civil Romano, Barcelona: Jaime Molinas, editor.

- García Garrido, M. J. (2003) Derecho Privado Romano. Casos, acciones, instituciones, $12 .^{\mathrm{a}}$ ed., Madrid: Ediciones Académicas.

- Girard P. F. (1906) Manuel Élémentaire de Droit Romain, 4. ${ }^{a}$ ed., Paris: Arthur Rousseau, éditeur.

- Gómez de la Serna (1863) Curso histórico exegético del derecho romano comparado con el español, $3 .^{\text {a }}$ ed., Madrid: : imprenta de la compañía de impresores y libreros del reino.

- Grenier, J. (1874) Du louage d'ouvrage et d'industrie en droit romain et en droit français, Thèse pour le doctorat, Faculté de Droit de Toulouse, Bergerac: Imprimer du Faisand.

- Guzmán Brito, A. (1996) Derecho Privado Romano, 6. a ed., Santiago: Jurídica de Chile.

- Heineccio, J. G. (1829) Elementos de Derecho Romano, traducidos y anotados por J. A. S, Madrid: Imprenta de D. Eusebio Aguayo.

- Kaser, M. (1968) Derecho romano privado, versión de la 5. ${ }^{a}$ ed. alemana por José Santa Cruz Teijeiro, Madrid: Reus.

- Mackeldey, F.(1846) Elementos del Derecho Romano, 2. a ed., Madrid: Sociedad Literaria y Tipográfica.

- Martin, S. (2001), "Imperitia: the responsability of skilled workers in classical roman law", American Journal of Philology, v. 122, pp. 107-129.

(1986) “The case of the collapsing watercourse: Builder's responsability for damage in classical roman law", Law and History Review, v. 4, n. 2, pp. 423-437.

- Martín Santisteban, S. (2004) "Responsabilidad en el contrato de depósito, su génesis histórica”, Anuario de Derecho civil, pp. 133-178.

- Martínez Vela, J. A. (2010) "Breves reflexiones sobre la merces en el contrato de locatio conductio", Revista General de Derecho romano, n. 14.

- May, G. (1890), Éléments de Droit romain, Paris: Larouse et Forcel libraires. 
- Metro, A. (2008) "El depósito retribuido desde el Derecho romano hasta los modernos códigos", Revista General de Derecho romano, n. 10.

- Michon, L. (1890) Droit romain: du louage d'ouvrage, locatio conductio operis faciendi. Droit français: des enquêtes parlamentaires, étude de Législation comparée. Thése pour le doctorat, Paris: Arthur Rousseau, éditeur.

- Miquel, J. (1992) Derecho Privado Romano, Madrid: Marcial Pons.

- Miron De l'espinay, A. (1873) Du louage d'ouvrage et industrie en droit romain. Des Entreprises sur devis et marchés en droit français. Thése pour le doctorat, Paris: A. Parent, imprimeur.

- Navarro, R./De Lara, R. J./De Zafra, J. Á. (1842) Curso Completo elemental del Derecho Romano, Madrid: Imprenta del colegio de sordomudos.

- Olivier-Martin, F (1936) "Des divisions du Louage en Droit Romain", Revue Historique de Droit Français et Étranger, pp. 419475.

- Ortega Carrillo de Albornoz, A. (2007) Derecho privado Romano, 2. ${ }^{\mathrm{a}}$ ed., Málaga: Ediciones del Genal.

- Ortolan, M. (1847) Explicación histórica de las instituciones del emperador Justiniano, traducido de la tercera edición por Pérez de Anaya, Madrid: La Ilustración.

- Petit, E. (1903), Traité elementaire de Droit romain, 4. ${ }^{a}$ ed., Paris: Arthur Rousseau, éditeur.

- Phillimore, J. G. (1863) Private Law among the romans from the pandects, London and Cambridge: Macmillan and Co.

- Pinna Parpaglia, P. (1983) Vitia ex ipsa re aspetti della locazione in diritto romano, Milán: Giuffrè.

- Pókecz Kovács, A. (2001) "Quelques observations sur la division de la locatio conductio", Studia Iuridica Auctoritate Universitatis Pecs Publicata, v. 127, pp. 217-230.

- Puliatri, S. (2009) "Custodiam praestare, para una definición de los límites de la responsabilidad por custodia en el derecho romano", Revista General de Derecho romano, n. 13.

- Ribalta Haro, J. (2012), "La formación de la tripartición locativa: desde el Derecho Romano hasta la codificación civil", en Vaquer, A./Bosch, E./SÁnchez, M. P. (coords.), Derecho Europeo de Contratos. Libros II y IV del Marco Común de Referencia, t. 2, Barcelona: Atelier, pp. 1095-1135.

- Robaye, R. (1991) "Le foulon et le bijoutier à Rome: les risques du métier”, Revue Belge de philology et d'histoire, n. 69, pp. 131-136.

- Rodríguez Ennes, L. (2009), "El singular renacimiento de la autonomía de la voluntad y la locatio conductio operarum et operis 
como consecuencia de la presente depresión económica”, Revista de Derecho de la Pontificia Universidad Católica de Valparaiso, n. 32, pp. 183-208.

- Samper Polo, F. (2009) Instituciones jurídicas de Gayo, texto y traducción, México D. F: Editorial Jurídica de las Américas.

- Schulz, F. (1969) Derecho romano clásico, Barcelona: Bosch.

- Silver. M. (1995) Economic Structures of Antiquity, Westport: Greenwood Publishing Group.

- Someting, E. F. (1698) Introductio in Universum Jus, Seriem IV. Librorum \& Titulorum institutionum imperalium, Salisburgi.

- Stoop, B. C (1998) "Non solet locatio dominium mutare. Some remarks on specificatio in classical roman law", Tijdschrift voor Rechtsgeschiedenis, n. 3, pp. 3-24.

- Torrent Ruiz, A. (2011) "La polémica sobre la tricotomía «res», "operae», «opus» y los orígenes de la «locatio-conductio»", Teoria e Storia del Diritto Privato, n. 4, pp. 1-28.

- Trigo García, M. a B. (1999) Contratos de servicios. Perspectiva jurídica actual, Granada: Comares.

- Vigneron, R. (1988) "La «Locatio conductio» secondo i romani", Labeo, n. 34, pp. 361-372.

- Voet, J. (1777) Commentarius ad pandectas, Coloniae Allogrobum (t. 1).

- Warnkoenig, L. A. (1827) Éléments de droit romain privé (traduit du latin sur la seconde edition), Paris: Chez Deschamps, Libraire.

- Wubbe, F. (1982) "Opus selón la définition de Labeón (D. 50.16.1.5)”, Tijdschrift voor Rechtsgeschiedenis, n. 50, pp. 241-251.

- Zimmermann, R. (1990) The law of obligations. Roman foundations of the civilian tradition, $1 .^{\mathrm{a}}$ ed. (reimpresión de 1992) Cape Town: Juta and Co. 